\title{
Decadal oxygen change in the eastern tropical North Atlantic
}

\author{
Johannes Hahn ${ }^{1}$, Peter Brandt ${ }^{1,2}$, Sunke Schmidtko ${ }^{1}$, and Gerd Krahmann ${ }^{1}$ \\ ${ }^{1}$ GEOMAR Helmholtz Centre for Ocean Research Kiel, Kiel, Germany \\ ${ }^{2}$ Christian-Albrechts-Universität zu Kiel, Kiel, Germany
}

Correspondence to: Johannes Hahn (jhahn@geomar.de)

Received: 20 December 2016 - Discussion started: 10 January 2017

Revised: 24 May 2017 - Accepted: 29 May 2017 - Published: 6 July 2017

\begin{abstract}
Repeat shipboard and multi-year moored observations obtained in the oxygen minimum zone (OMZ) of the eastern tropical North Atlantic (ETNA) were used to study the decadal change in oxygen for the period 2006-2015. Along $23^{\circ} \mathrm{W}$ between 6 and $14^{\circ} \mathrm{N}$, oxygen decreased with a rate of $-5.9 \pm 3.5 \mu \mathrm{mol} \mathrm{kg}{ }^{-1}$ decade $^{-1}$ within the depth covering the deep oxycline $(200-400 \mathrm{~m})$, while below the OMZ core (400-1000 m) oxygen increased by $4.0 \pm 1.6 \mu \mathrm{mol} \mathrm{kg}{ }^{-1}$ decade $^{-1}$ on average. The inclusion of these decadal oxygen trends in the recently estimated oxygen budget for the ETNA OMZ suggests a weakened ventilation of the upper $400 \mathrm{~m}$, whereas the ventilation strengthened homogeneously below $400 \mathrm{~m}$. The changed ventilation resulted in a shoaling of the ETNA OMZ of $-0.03 \pm 0.02 \mathrm{~kg} \mathrm{~m}^{-3}$ decade $^{-1}$ in density space, which was only partly compensated by a deepening of isopycnal surfaces, thus pointing to a shoaling of the OMZ in depth space as well $\left(-22 \pm 17 \mathrm{~m} \mathrm{decade}^{-1}\right)$. Based on the improved oxygen budget, possible causes for the changed ventilation are analyzed and discussed. Largely ruling out other ventilation processes, the zonal advective oxygen supply stands out as the most probable budget term responsible for the decadal oxygen changes.
\end{abstract}

\section{Introduction}

Over the past decades, tropical oceans have been subject to a conspicuous deoxygenation (Brandt et al., 2015; Stramma et al., 2008, 2012) at thermocline to intermediate depths comprising the upper $700 \mathrm{~m}$ of the ocean. These well-documented changes manifest themselves in a profound decrease of dissolved oxygen and a volumetric increase of open-ocean tropical oxygen minimum zones (OMZs)
(Stramma et al., 2010). OMZs are located in the weakly ventilated shadow zones of the ventilated thermocline (Luyten et al., 1983) in the eastern tropical Atlantic and Pacific ocean basins off the Equator as well as in the northern Indian Ocean between 100 and $900 \mathrm{~m}$ (Karstensen et al., 2008). Their existence predominantly results from a weak oxygen supply to these sluggish flow regimes accompanied by locally enhanced oxygen consumption in proximity to coastal and open-ocean upwelling regions (Helly and Levin, 2004).

Among all OMZs, the open-ocean OMZ of the eastern tropical North Atlantic (ETNA), with its core position around $10^{\circ} \mathrm{N}, 20^{\circ} \mathrm{W}$ and $400 \mathrm{~m}$ (Brandt et al., 2015), was observed as the region with the strongest multi-decadal oxygen decrease since the 1960s (Stramma et al., 2008). Within the recent decade, this region exhibited record low oxygen concentrations well below $40 \mu \mathrm{mol} \mathrm{kg}^{-1}$ (Stramma et al., 2009). Beyond that, Brandt et al. (2015) found for the past decade an even stronger oxygen decrease in the depth of the deep oxycline (corresponding to the upper OMZ boundary) and a weak oxygen increase below the OMZ core, superimposed on the multi-decadal oxygen decrease. Compared to the Pacific and Indian OMZs, the open-ocean ETNA OMZ - not to be mistaken with the shallow OMZ in the Mauritanian upwelling regime (Wallace and Bange, 2004) or episodically developing open-ocean dead zones at shallow depth (Karstensen et al., 2015; Schütte et al., 2016) - exhibits a smaller horizontal and vertical extent $(300-700 \mathrm{~m})$ and only moderate hypoxic (oxygen concentration $<60$ $120 \mu \mathrm{mol} \mathrm{kg}^{-1}$ ) conditions. In comparison to the Pacific, the smaller basin width of the tropical Atlantic results in quicker ventilation from the western boundary and overall younger water mass ages (Brandt et al., 2015; Karstensen et al., 2008). Hence, temporal changes of circulation and ventilation of the 
ETNA likely have a comparatively fast impact on the local oxygen concentration.

Various processes related to anthropogenic as well as natural climate variability might have contributed to the global multi-decadal oxygen decrease. It is generally accepted that decreasing oxygen solubility (thermal effect) in a warming ocean is not the dominant driver (Helm et al., 2011; Schmidtko et al., 2017) of the observed deoxygenation. Other anthropogenically driven mechanisms were identified instead by various model studies investigating changes in biogeochemical processes that impact the oxygen consumption (production effect) (Keeling and Garcia, 2002; Oschlies et al., 2008) as well as changes in ocean circulation, subduction and mixing (dynamic effect) (Bopp et al., 2002; Plattner et al., 2002; Frölicher et al., 2009; Matear and Hirst, 2003; Schmittner et al., 2008; Cabre et al., 2015). Despite a general agreement between different models on an anthropogenically driven and still ongoing global mean oxygen decrease, regional patterns of the modeled oxygen changes often do not agree with the observed trend patterns (Stramma et al., 2012).

Natural climate variability has been found to be an essential driver for oxygen variability on interannual to multidecadal timescales (Duteil et al., 2014a; Frölicher et al., 2009; Cabre et al., 2015; Stendardo and Gruber, 2012; Czeschel et al., 2012). Alternating phases of oxygen decrease and increase might be superimposed on the suggested anthropogenically forced multi-decadal oxygen decrease and might lead to a damping or reinforcing of such a trend on different timescales. Multi-decadal changes in circulation such as an intensification/weakening of the tropical zonal current system, the subtropical cells (STCs) or the meridional overturning circulation (MOC) (Chang et al., 2008; Rabe et al., 2008; Lübbecke et al., 2015) are related to changes in the ventilation and consequently lead to varying oceanic oxygen concentrations (Brandt et al., 2010; Duteil et al., 2014a). Nonetheless, biogeochemical and physical processes may also compensate each other, leading to a damped oxygen variability on interannual to decadal timescales (Duteil et al., 2014a; Cabre et al., 2015).

The mean horizontal oxygen distribution is mainly set by the mean current field (Wyrtki, 1962). In the tropical Atlantic, the upper ocean large-scale flow field (Schott et al., 2004, 2005; Brandt et al., 2015; Eden and Dengler, 2008) comprises (i) the northern and southern STCs, (ii) the western boundary current regime and (iii) the system of equatorial and off-equatorial mean zonal currents (Fig. 1). The STC describes the large-scale shallow overturning circulation, which connects the subtropical subduction regions of both hemispheres to the eastern equatorial upwelling regimes by equatorward thermocline and poleward surface flow (Schott et al., 2004; McCreary and Lu, 1994). As part of the northern STC, the North Equatorial Current (NEC) partly entrains thermocline water from the subtropics into the zonal current system south of the Cabo Verde archipelago either via the western boundary or via interior pathways (Pena-Izquierdo et al.,

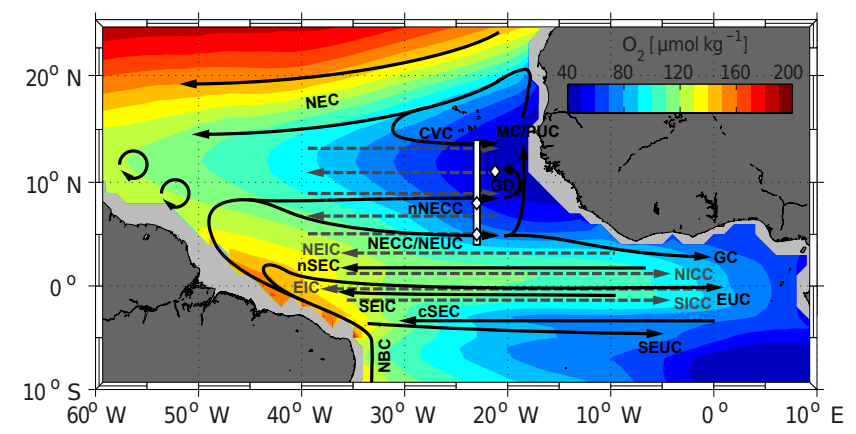

Figure 1. Oxygen concentration in $\mu \mathrm{mol} \mathrm{kg}{ }^{-1}$ (shaded colors) in the tropical Atlantic at potential density surface $27.1 \mathrm{~kg} \mathrm{~m}^{-3}$ (close to the deep oxygen minimum) obtained from MIMOC (monthly, isopycnal and mixed-layer ocean climatology) (Schmidtko et al., 2013, 2017). Superimposed arrows denote the mean current field (adapted from Brandt et al., 2015; Pena-Izquierdo et al., 2015). Surface and thermocline (about upper $300 \mathrm{~m}$ ) currents (black solid arrows) are the North Equatorial Current (NEC), Cape Verde Current (CVC), Mauritania Current/poleward undercurrent (MC/PUC), Guinea Dome (GD), North Equatorial Countercurrent/North Equatorial Undercurrent (NECC/NEUC), northern branch of the NECC (nNECC), northern and central branches of the South Equatorial Current (nSEC, cSEC), Equatorial Undercurrent (EUC), South Equatorial Intermediate Current (SEIC), South Equatorial Undercurrent (SEUC) and North Brazil Current (NBC). Current branches at intermediate depth (gray dashed arrows) are latitudinally alternating zonal jets (LAZJs) between 5 and $13^{\circ} \mathrm{N}$, North Equatorial Intermediate Current (NEIC), Equatorial Intermediate Current (EIC) as well as the Northern Intermediate Countercurrent (NICC) and Southern Intermediate Countercurrent (SICC). The white bar denotes the $23^{\circ} \mathrm{W}$ section between 4 and $14^{\circ} \mathrm{N}$. White diamonds mark positions of multi-year moored observations used in this study.

2015; Schott et al., 2004; Zhang et al., 2003), but most of this water does not reach the Equator. The western boundary current system, given by the North Brazil Current (NBC) and North Brazil Undercurrent (NBUC), acts as the major pathway for the interhemispheric northward transport of South Atlantic Water. It represents a superposition of the Atlantic MOC (AMOC), the southern STC and the recirculation of the southward interior Sverdrup transport (Schott et al., 2004).

The zonal current system in the tropical North Atlantic drives the water mass exchange between the well-ventilated western boundary and the eastern basin (Stramma and Schott, 1999). Between $5^{\circ} \mathrm{S}$ and $5^{\circ} \mathrm{N}$, strong mean as well as time-varying zonal currents exist from the surface to intermediate depth (Schott et al., 2003; Ascani et al., 2010, 2015; Johns et al., 2014; Bunge et al., 2008; Eden and Dengler, 2008; Brandt et al., 2010); the associated oxygen flux is responsible for the existence of a pronounced equatorial oxygen maximum (Brandt et al., 2008, 2012) therewith setting the southern boundary of the ETNA OMZ. Between $5^{\circ} \mathrm{N}$ and the Cabo Verde archipelago, wind-driven mean zonal currents are present down to a depth of about $300 \mathrm{~m}$ 
(the North Equatorial Countercurrent/North Equatorial Undercurrent (NECC/NEUC) centered at $5^{\circ} \mathrm{N}$ and the northern branch of the NECC (nNECC) centered at $9^{\circ} \mathrm{N}$ ). In accordance with the meridional migration of the Intertropical Convergence Zone (ITCZ), these currents exhibit strong seasonal to interannual variability in their strength and position (Hormann et al., 2012; Garzoli and Katz, 1983; Garzoli and Richardson, 1989; Richardson et al., 1992). Their connection to the western boundary seasonally alternates as well. Next to a more permanent supply of the Equatorial Undercurrent (EUC), water from the NBC retroflection is injected either into the NECC/NEUC or the nNECC. Below $300 \mathrm{~m}$, latitudinally alternating zonal jets (LAZJs), occasionally referred to as latitudinally stacked zonal jets or North Equatorial Undercurrent jets, dominate the mean current field. They are a pervasive feature in all tropical oceans at intermediate depth and occur as nearly depth-independent zonal current bands with weak mean zonal velocity of a few $\mathrm{cm} \mathrm{s}^{-1}$ alternating eastward/westward with a meridional scale of about $2^{\circ}$ (Maximenko et al., 2005; Ollitrault and de Verdiere, 2014; Brandt et al., 2010; Qiu et al., 2013). Within the upper $300 \mathrm{~m}$, the signature of the LAZJs is often masked by a strong winddriven circulation (Rosell-Fieschi et al., 2015). The generation of the LAZJs is not fully understood yet and different forcing mechanisms have been suggested (Kamenkovich et al., 2009; Qiu et al., 2013; Ascani et al., 2010). Nevertheless, eddy-permitting ocean circulation models partly simulate these jets, leading to an improved simulated oxygen distribution in global biogeochemical circulation models (Duteil et al., 2014b) and indicating that LAZJs play an important role in ventilating the ETNA from the western boundary.

Two different water masses spread into the ETNA between about 100 and $1000 \mathrm{~m}$ depth: North Atlantic Water (NAW) and South Atlantic Water (SAW), which have their origin either in the North or South Atlantic (Kirchner et al., 2009). Within the depth range 150 and $500 \mathrm{~m}$ (corresponding to potential density layers between 25.8 and $27.1 \mathrm{~kg} \mathrm{~m}^{-3}$ ), these water masses correspond to North Atlantic Central Water (NACW) and South Atlantic Central Water (SACW). Both NACW and SACW exhibit almost linear $\theta-S$ relationships, where NACW is distinctly saltier than SACW. The fraction of SACW in the upper central water (UCW) layer between 150 and $300 \mathrm{~m}$ is larger than the fraction of SACW in the lower central water (LCW) layer between 300 and $500 \mathrm{~m}$. This layering of SACW-dominated water in the upper layer above NACW-dominated water in the lower layer suggests a stronger ventilation from the South Atlantic in the UCW. The boundary between both regimes, located at about $300 \mathrm{~m}$ (corresponding to a potential density of about $26.8 \mathrm{~kg} \mathrm{~m}^{-3}$ ), is marked by the presence of the deep oxycline and indicates a vertically abrupt change in the circulation and associated ventilation (Pena-Izquierdo et al., 2015).

Below the central water $(\mathrm{CW})$ layer, low-saline Antarctic Intermediate Water (AAIW) is found at densities between 27.1 and $27.7 \mathrm{~kg} \mathrm{~m}^{-3}$ (600-1500 m) (Stramma et al., 2005;
Karstensen et al., 2008; Schmidtko and Johnson, 2012). AAIW spreads to latitudes of about $20^{\circ} \mathrm{N}$, becoming less oxygenated toward the north.

The recently derived observationally based oxygen budget for the ETNA (Hahn et al., 2014; Brandt et al., 2015; Fischer et al., 2013; Karstensen et al., 2008; Brandt et al., 2010) has shed light on the different budget terms, which define (i) oxygen supply, (ii) oxygen consumption and (iii) oxygen tendency. In the upper $350 \mathrm{~m}$, mean zonal currents (NECC/NEUC, nNECC) play the dominant role for the ventilation of the ETNA and thus for the supply at the upper boundary of the OMZ. In the depth range of the OMZ core at about $400 \mathrm{~m}$, lateral and vertical mixing dominate the oxygen supply toward the OMZ; advection plays only a minor role. Below the OMZ core, lateral and vertical oxygen supplies weaken with depth, and lateral advection becomes of similar importance compared to the other supply terms roughly below 600 to $700 \mathrm{~m}$. A recent model study (Pena-Izquierdo et al., 2015) proposed the presence of mean vertical advection with reversed flow direction in the UCW and LCW, which is related to two stacked subtropical cells in this depth range. Vertical advection may play an additional role in supplying the ETNA OMZ, but so far this process has not been considered in the oxygen budget.

Only few processes have been investigated quantitatively (Brandt et al., 2010) that might be responsible for driving oxygen variability on decadal to multi-decadal timescales in the ETNA. Brandt et al. (2015) qualitatively discussed and proposed the following mechanisms: (i) decadal to multidecadal AMOC changes; (ii) transport variability of Indian Ocean CW entrained into the South Atlantic (variability in the Agulhas leakage); (iii) changes in the strength of LAZJs; (iv) changes in the strength and location of the wind-driven gyres; (v) variability of ventilation efficiency due to changes in solubility or subduction; and (vi) multi-decadal changes in the strength of Atlantic STCs.

The aim of this study is to contribute to a more comprehensive understanding of the oxygen changes during the last decade and of the dynamical processes that drive this variability. This encompasses three major goals: (i) description of the regional pattern of the decadal oxygen trend; (ii) determination of associated trends in salinity and circulation; (iii) discussion of implications of the decadal oxygen trend for the oxygen budget of the ETNA. The paper is structured as follows. Section 2 describes the observational and climatological data sets used in this study as well as the methods to analyze them. Further, the oxygen budget and individual budget terms for the ETNA are introduced, as they were mainly derived in recent studies. In Sect. 3, the results of the present study are presented. They are comprehensively discussed in Sect. 4. Section 5 gives a short summary and conclusive remarks. 

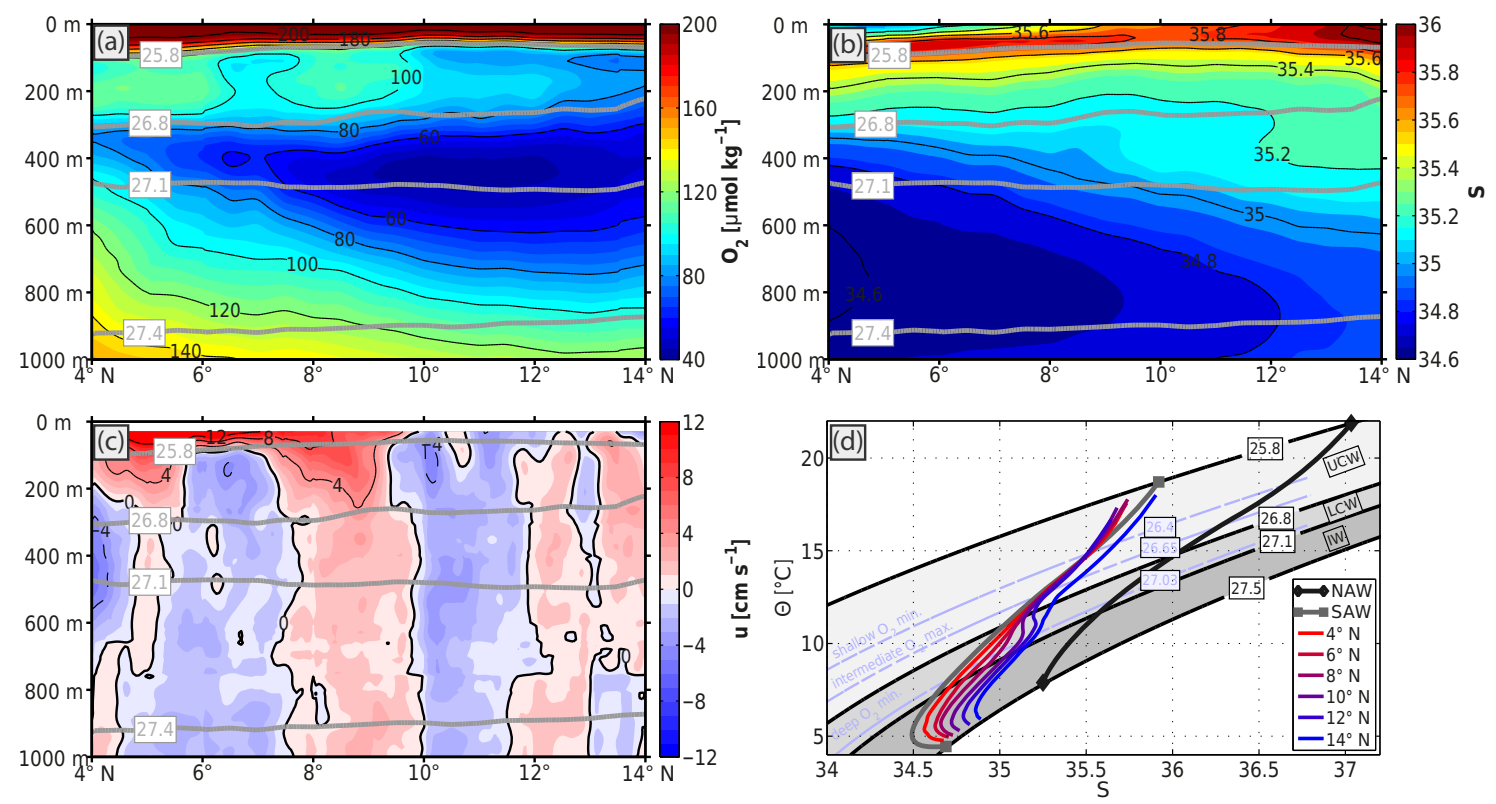

Figure 2. Mean sections of (a) oxygen, (b) salinity and (c) zonal velocity along $23^{\circ} \mathrm{W}$ between 4 and $14^{\circ} \mathrm{N}$. Black contours denote isolines of the respective mean field. Gray solid contours mark mean surfaces of potential density in $\mathrm{kg} \mathrm{m}^{-3}$. Note that no data of mean zonal velocity were derived for the upper $30 \mathrm{~m}$. (d) Mean $\theta-S$ characteristics for North Atlantic Water (NAW) and South Atlantic Water (SAW) and for different latitudes along $23^{\circ} \mathrm{W}$ (details of reference regimes for NAW and SAW are given in the text). Data from about the upper $100 \mathrm{~m}$ of the water column were excluded. Black solid lines denote isopycnal surfaces, which define the different water mass regimes for UCW (upper central water), LCW (lower central water) and IW (intermediate water). Blue dashed lines denote isopycnal surfaces, which define different oxygen regimes with respect to the mean vertical oxygen profile in the ETNA.

\section{Data and methods}

This study uses a combined set of hydrographic, oxygen and velocity data, which consists of (i) repeat shipboard and moored observations, (ii) the MIMOC (monthly, isopycnal and mixed-layer ocean climatology), (iii) float observations provided by the Argo program and (iv) satellite derived surface velocities provided by Aviso. Further, data products of the different oxygen budget terms are used, which were derived in recent studies.

\subsection{Repeat ship sections along $23^{\circ} \mathrm{W}$}

Hydrographic, oxygen and velocity data were obtained during repeated research cruises carried out mainly along $23^{\circ} \mathrm{W}$ in the ETNA in the period from 2006 to 2015 (1999 to 2015 for velocity; see Table 1 for details). The data set is an update of the $23^{\circ} \mathrm{W}$ ship section data used in Brandt et al. (2015). In the present study, data records from 4 to $14^{\circ} \mathrm{N}$ (ETNA OMZ regime) were taken into account.

Hydrographic and oxygen data were acquired during CTD (conductivity-temperature-depth) casts, typically performed on a uniform latitude grid with half-degree resolution. Velocity data were acquired with different Acoustic Doppler Current Profiler (ADCP) systems; vessel-mounted ADCPs (vm-ADCPs) recorded velocities continuously throughout the section and pairs of lowered ADCPs (1-ADCPs), attached to the CTD rosette, recorded during CTD casts.

Based on these data sets, meridional sections of hydrography, oxygen and velocity were linearly interpolated for each ship section onto a homogeneous depth-latitude grid with a resolution of $10 \mathrm{~m}$ and $0.05^{\circ}$, respectively. Details of the methodology as well as on measurement errors are given in Brandt et al. (2010). For a single research cruise, the accuracy of hydrographic and oxygen data was assumed to be generally better than $0.002^{\circ} \mathrm{C}, 0.002$ and $2 \mu \mathrm{mol} \mathrm{kg}{ }^{-1}$ for temperature, salinity and dissolved oxygen, respectively. The accuracy of $1 \mathrm{~h}$ averaged velocity data from vm-ADCPs and single velocity profiles from 1-ADCPs was better than 2-4 and $5 \mathrm{~cm} \mathrm{~s}^{-1}$, respectively.

Mean sections along $23^{\circ} \mathrm{W}$ were calculated (Fig. 2a to c) from 13 (hydrography/oxygen) and 31 (velocity) individual ship sections, respectively (Table 1). For the depth range $100-1000 \mathrm{~m}$, the averaging of all sections yielded an average standard error of the mean fields (which is considered to result mostly from oceanic variability) of about $1.8 \mu \mathrm{mol} \mathrm{kg}-1$, $0.06^{\circ} \mathrm{C}, 0.009$ and $1.1 \mathrm{~cm} \mathrm{~s}^{-1}$ for oxygen, temperature, salinity and zonal velocity, respectively.

Moreover, a meridional section of the decadal oxygen and salinity trend was estimated. First, the data from each ship section were interpolated on a density grid (grid spacing $0.01 \mathrm{~kg} \mathrm{~m}^{-3}$ ) by applying an average depth-density relation 
Table 1. Research cruises carried out in the eastern tropical North Atlantic between 4 and $14^{\circ} \mathrm{N}$ mainly along the $23^{\circ} \mathrm{W}$ section between 1999 and 2015. Different columns denote the latitude section along mean longitude (lat./long.) and maximum profile depth available/used here (depth in meters) for velocity observations performed with vessel-mounted and lowered Acoustic Doppler Current Profilers (vm-ADCPs/lADCPs) as well as for hydrographic and oxygen observations performed with a conductivity-temperature-depth sonde $\left(\mathrm{CTD} / \mathrm{O}_{2}\right)$. Note that during some research cruises, two velocity and/or hydrographic sections were obtained.

\begin{tabular}{|c|c|c|c|c|}
\hline \multirow[t]{2}{*}{ Vessel and cruise (date) } & \multicolumn{2}{|c|}{ vm-ADCP/l-ADCP } & \multicolumn{2}{|l|}{$\mathrm{CTD} / \mathrm{O}_{2}$} \\
\hline & Lat./long. & $\begin{array}{r}\text { Depth } \\
(\mathrm{m})\end{array}$ & Lat./long. & $\begin{array}{r}\text { Depth } \\
(\mathrm{m})\end{array}$ \\
\hline $\begin{array}{l}\text { Thalassa } \\
\text { (Jul-Aug 1999) }\end{array}$ & $4-6^{\circ} \mathrm{N} / 23^{\circ} \mathrm{W}$ & 1000 & - & - \\
\hline $\begin{array}{l}\text { Meteor 55 } \\
\text { (Oct 2002) }\end{array}$ & $4-10^{\circ} \mathrm{N} / 24^{\circ} \mathrm{W}$ & 650 & - & - \\
\hline $\begin{array}{l}\text { Ron Brown } \\
\text { (Jun-Aug 2003) }\end{array}$ & $4-10^{\circ} \mathrm{N} / \sim 27^{\circ} \mathrm{W}$ & 1000 & - & - \\
\hline $\begin{array}{l}\text { Polarstern Ant XXII/5 } \\
\text { (Jun 2005) }\end{array}$ & $4-14^{\circ} \mathrm{N} / 23^{\circ} \mathrm{W}$ & 300 & - & - \\
\hline $\begin{array}{l}\text { Ron Brown } \\
\text { (Jun 2006) }\end{array}$ & $\begin{array}{l}4-13.5^{\circ} \mathrm{N} / 23^{\circ} \mathrm{W} \\
4-14^{\circ} \mathrm{N} / 23^{\circ} \mathrm{W}\end{array}$ & $\begin{array}{l}750 \\
750\end{array}$ & $\begin{array}{l}4-13.5^{\circ} \mathrm{N} / 23.0^{\circ} \mathrm{W} \\
4-14^{\circ} \mathrm{N} / 23.0^{\circ} \mathrm{W}\end{array}$ & $\begin{array}{l}1000 \\
1000\end{array}$ \\
\hline $\begin{array}{l}\text { Meteor 68/2 } \\
\text { (Jun-Jul 2006) }\end{array}$ & $4-14^{\circ} \mathrm{N} / 23^{\circ} \mathrm{W}$ & 1000 & $4-14^{\circ} \mathrm{N} / 23.2-22.0^{\circ} \mathrm{W}$ & 1000 \\
\hline $\begin{array}{l}\text { Ron Brown } \\
\text { (May 2007) }\end{array}$ & $4-14^{\circ} \mathrm{N} / 23^{\circ} \mathrm{W}$ & 750 & $4-14^{\circ} \mathrm{N} / 23.1-22.6^{\circ} \mathrm{W}$ & 1000 \\
\hline $\begin{array}{l}\text { L'Atalante } \\
\text { (Feb-Mar 2008) }\end{array}$ & $\begin{array}{l}4-14^{\circ} \mathrm{N} / 23^{\circ} \mathrm{W} \\
4-14^{\circ} \mathrm{N} / 23^{\circ} \mathrm{W}\end{array}$ & $\begin{array}{r}400 \\
1000\end{array}$ & $4-14^{\circ} \mathrm{N} / 23^{\circ} \mathrm{W}$ & 1000 \\
\hline $\begin{array}{l}\text { Maria S. Merian 08/1 } \\
\text { (Apr-May 2008) }\end{array}$ & $\begin{array}{l}7.5-14^{\circ} \mathrm{N} / 23^{\circ} \mathrm{W} \\
8-14^{\circ} \mathrm{N} / 25^{\circ} \mathrm{W}\end{array}$ & $\begin{array}{l}600 \\
800\end{array}$ & - & - \\
\hline $\begin{array}{l}\text { Polarstern Ant XXIV/4 } \\
\text { (Apr-May 2008) }\end{array}$ & $4-14^{\circ} \mathrm{N} / 24-22^{\circ} \mathrm{W}$ & 240 & - & - \\
\hline $\begin{array}{l}\text { Maria S. Merian 10/1 } \\
\text { (Nov-Dec 2008) }\end{array}$ & $4-14^{\circ} \mathrm{N} / 23^{\circ} \mathrm{W}$ & 650 & $4-14^{\circ} \mathrm{N} / 23^{\circ} \mathrm{W}$ & 1000 \\
\hline $\begin{array}{l}\text { Polarstern Ant XXV/5 } \\
\text { (May 2009) }\end{array}$ & $4-14^{\circ} \mathrm{N} / 23^{\circ} \mathrm{W}$ & 250 & - & - \\
\hline $\begin{array}{l}\text { Ron Brown } \\
\text { (Jul-Aug 2009) }\end{array}$ & $4-14^{\circ} \mathrm{N} / 23^{\circ} \mathrm{W}$ & 700 & $4-14^{\circ} \mathrm{N} / 23^{\circ} \mathrm{W}$ & 1000 \\
\hline $\begin{array}{l}\text { Meteor 80/1 } \\
\text { (Oct-Nov 2009) }\end{array}$ & $\begin{array}{l}4-14^{\circ} \mathrm{N} / 23^{\circ} \mathrm{W} \\
4-14^{\circ} \mathrm{N} / 23^{\circ} \mathrm{W}\end{array}$ & $\begin{array}{r}1000 \\
600\end{array}$ & $4-14^{\circ} \mathrm{N} / 23^{\circ} \mathrm{W}$ & 1000 \\
\hline $\begin{array}{l}\text { Polarstern Ant XXVI/1 } \\
\text { (Nov 2009) }\end{array}$ & $4-14^{\circ} \mathrm{N} / 23^{\circ} \mathrm{W}$ & 250 & - & - \\
\hline $\begin{array}{l}\text { Meteor 81/1 } \\
(\text { Feb-Mar 2010) }\end{array}$ & $4-13^{\circ} \mathrm{N} / 22^{\circ} \mathrm{W}$ & 1000 & - & - \\
\hline $\begin{array}{l}\text { Polarstern Ant XXVI/4 } \\
\text { (Apr-May 2010) }\end{array}$ & $4-13.5^{\circ} \mathrm{N} / 23^{\circ} \mathrm{W}$ & 250 & - & - \\
\hline $\begin{array}{l}\text { Ron Brown } \\
\text { (May 2010) }\end{array}$ & $4-14^{\circ} \mathrm{N} / 23^{\circ} \mathrm{W}$ & 1000 & - & - \\
\hline $\begin{array}{l}\text { Maria S. Merian 18/2 } \\
\text { (May-Jun 2011) }\end{array}$ & $\begin{array}{l}4-5^{\circ} \mathrm{N} / 23^{\circ} \mathrm{W} \\
4-14^{\circ} \mathrm{N} / 23^{\circ} \mathrm{W}\end{array}$ & $\begin{array}{l}1000 \\
1000\end{array}$ & - & - \\
\hline
\end{tabular}


Table 1. Continued.

\begin{tabular}{llrlr}
\hline Vessel and cruise (date) & \multicolumn{2}{c}{ vm-ADCP/l-ADCP } & CTD/O 2 & \\
\cline { 2 - 5 } & Lat./long. & $\begin{array}{r}\text { Depth } \\
(\mathrm{m})\end{array}$ & Lat./long. & $\begin{array}{r}\text { Depth } \\
(\mathrm{m})\end{array}$ \\
\hline $\begin{array}{l}\text { Maria S. Merian 18/3 } \\
\text { (Jun-Jul 2011) }\end{array}$ & $4-14^{\circ} \mathrm{N} / 23^{\circ} \mathrm{W}$ & 600 & $4-14^{\circ} \mathrm{N} / 23^{\circ} \mathrm{W}$ & 1000 \\
\hline $\begin{array}{l}\text { Ron Brown } \\
\text { (Jul-Aug 2011) }\end{array}$ & $4-14^{\circ} \mathrm{N} / 23^{\circ} \mathrm{W}$ & 700 & - & \\
\hline $\begin{array}{l}\text { Maria S. } \text { Merian 22 } \\
(\text { Oct-Nov 2012) }\end{array}$ & $4-8^{\circ} \mathrm{N} / 23^{\circ} \mathrm{W}$ & 1000 & $4-14^{\circ} \mathrm{N} / 23^{\circ} \mathrm{W}$ & 1000 \\
\hline $\begin{array}{l}\text { Meteor 106 } \\
\text { (Apr-May 2014) }\end{array}$ & $4-14^{\circ} \mathrm{N} / 23^{\circ} \mathrm{W}$ & 1000 & & 1000 \\
\hline $\begin{array}{l}\text { Polarstern PS88.2 } \\
\text { (Nov 2014) }\end{array}$ & $4-14^{\circ} \mathrm{N} / 23^{\circ} \mathrm{W}$ & 1000 & $4-14^{\circ} \mathrm{N} / 23^{\circ} \mathrm{W}$ & 1000 \\
\hline $\begin{array}{l}\text { Meteor 119 } \\
\text { (Sep-Oct 2015) }\end{array}$ & $4-14^{\circ} \mathrm{N} / 23^{\circ} \mathrm{W}$ & 1000 & $4-14^{\circ} \mathrm{N} / 23^{\circ} \mathrm{W}$ & 1000 \\
\hline
\end{tabular}

in the depth range $0-1000 \mathrm{~m}$. Then, linear regressions were calculated (using a $95 \%$ confidence level to determine their significance) at each grid point in latitude-density space. The resulting sections were subsequently projected onto the depth grid.

In order to relate changes in oxygen to changes in salinity, shipboard observations were used to calculate the correlation between both variables at every grid point of the section. All calculations were evaluated in density space and the results were subsequently projected onto the depth grid.

\subsection{Moored observations}

Multi-year moored observations (2009-2015) were performed in the ETNA to record hourly to interannual oxygen variability at three different positions: $5^{\circ} \mathrm{N} / 23^{\circ} \mathrm{W}$, $8^{\circ} \mathrm{N} / 23^{\circ} \mathrm{W}$ and $11^{\circ} \mathrm{N} / 21^{\circ} \mathrm{W}$ (see Table 2 for details about available data). All moorings were equipped with oxygen (AADI Aanderaa optodes of model types 3830 and 4330) and CTD sensors (Sea-Bird SBE37 microcats), which were attached next to each other on the mooring cable to allow an appropriate estimate of the dissolved oxygen on density surfaces. At every mooring site, eight evenly distributed optode/microcat combinations were installed in the depth range between 100 to $800 \mathrm{~m}$, delivering multi-year oxygen time series with a temporal resolution of up to $5 \mathrm{~min}$.

Moorings were serviced and redeployed generally every 18 months. In order to achieve the highest possible longterm sensor accuracy, optodes and microcats were carefully calibrated against oxygen and CTD measurements (from a $\mathrm{CTD} / \mathrm{O}_{2}$ unit) by attaching them to the CTD rosette during regular CTD casts immediately prior to and after the mooring deployment period. Optodes were additionally calibrated in the laboratory on board to expand the range of reference cali- bration points. Details of the optode calibration methodology are given in Hahn et al. (2014). The root mean square error of temperature and salinity measurements (microcats) as well as dissolved oxygen measurements (optodes) was about $0.003{ }^{\circ} \mathrm{C}, 0.006$ and $3 \mu \mathrm{mol} \mathrm{kg}{ }^{-1}$, respectively.

Oxygen and salinity time series from the three mooring sites were 10-day low-pass filtered and subsequently interpolated in depth space between 100 and $800 \mathrm{~m}$. Based on this uniformly gridded data set, oxygen and salinity anomalies were calculated by (i) interpolating the moored and shipboard observations on a regular density grid (grid spacing $0.01 \mathrm{~kg} \mathrm{~m}^{-3}$ ), (ii) subtracting the respective mean profiles in density space obtained solely from shipboard observations and (iii) projecting the calculated anomalies back onto the depth grid (by applying an average depth-density relation). This calculation removed the effect of isopycnal heave due to internal waves, mesoscale eddies or seasonal variability in the circulation. Depth averages of these oxygen and salinity anomaly time series were calculated for the two depth layers (200-400 and 500-800 m).

Linear trends were fitted to the oxygen and salinity anomaly time series from the combined observational data set of moored and shipboard observations for the two respective depth layers. A weighted linear regression scheme was used, where a single ship section was weighted similar to 30 days of moored observations. Intervals on a $95 \%$ confidence level were calculated for the estimated trends.

Moored observations were additionally used to calculate a correlation between oxygen and salinity (see also Sect. 2.1 for a similar analysis based on shipboard observations). As we consider only long-term variability, the correlation was computed from the 90-day median of the mooring time series at the three respective latitudes. All calculations were 
Table 2. Moored observations carried out in the eastern tropical North Atlantic between 2009 and 2015. Column "depth (m)" denotes the instrument depth at the respective mooring. Columns " $\mathrm{O}_{2}$ " and " $T, S$ " denote the percentage of available oxygen and hydrographic data, respectively, compared to the total time period. A cross (" $x$ ") marks data coverage of better than $99 \%$.

\begin{tabular}{lrrr}
\hline Mooring position (time period) & Depth $(\mathrm{m})$ & $\mathrm{O}_{2}$ & $T, S$ \\
\hline $5^{\circ} \mathrm{N}, 23^{\circ} \mathrm{W}$ (Nov 2009-Sep 2015) & 100 & $87 \%$ & $81 \%$ \\
& 200 & $81 \%$ & $97 \%$ \\
& 300 & $76 \%$ & $x$ \\
400 & $x$ & $x$ \\
& 500 & $75 \%$ & $x$ \\
$8^{\circ} \mathrm{N}, 23^{\circ} \mathrm{W}($ Nov 2009-Oct 2012) & 600 & $x$ & $x$ \\
& 700 & $75 \%$ & $x$ \\
& 800 & $x$ & $74 \%$ \\
\hline $11^{\circ} \mathrm{N}, 21.2^{\circ} \mathrm{W}($ Nov 2012-Sep 2015) & 100 & $x$ & $x$ \\
& 200 & $x$ & $x$ \\
& 300 & $x$ & $x$ \\
& 400 & $x$ & $x$ \\
500 & $x$ & $x$ \\
& 600 & $x$ & $14 \%$ \\
& 700 & $x$ & $71 \%$ \\
& 800 & $x$ & $x$ \\
\hline & 100 & $x$ & $x$ \\
& 200 & $x$ & $x$ \\
& 300 & $x$ & $x$ \\
400 & $x$ & $x$ \\
& 500 & $x$ & $x$ \\
& 600 & $x$ & $x$ \\
& 700 & $72 \%$ & $x$ \\
& 800 & $x$ & $x$ \\
\hline
\end{tabular}

evaluated in density space and the results were subsequently projected onto the depth grid.

\subsection{MIMOC}

The monthly, isopycnal and mixed-layer ocean climatology (MIMOC) (Schmidtko et al., 2013) was used as a reference mean state in order to (i) perform a water mass analysis and (ii) quantify the temporal evolution of salinity anomalies in the tropical Atlantic. The climatological fields of potential temperature and salinity were interpolated on respective density layers, and mean $\theta-S$ characteristics were defined for the two predominant water masses NAW and SAW found in the tropical Atlantic.

\subsection{Argo float data set}

All Argo data (Roemmich et al., 2009) available for the study region were considered (https://doi.org/doi:10.13155/29825). Argo float data are collected and made freely available by the international Argo project and the national programs that contribute to it. For the analysis, only delayed mode data with a data quality flag of "probably good" or better were used.
The Argo profile data were used in this study to quantify the temporal evolution of salinity anomalies in the tropical Atlantic on two characteristic density surfaces (26.8 and $27.2 \mathrm{~kg} \mathrm{~m}^{-3}$ ). Anomalies of salinity were calculated with respect to the mean state given by MIMOC (see Sect. 2.3) for the period 2004-2016. Subsequently, mean salinity anomalies were calculated for different periods and a decadal tendency was estimated for the whole period.

\subsection{Surface geostrophic velocity from altimeter products}

Surface geostrophic velocities derived from satellite altimetry were used in this study to estimate the decadal change of the near-surface circulation and ventilation of the ETNA. The altimeter product was produced by Ssalto/Duacs and distributed by Aviso, with support from Cnes (http://www.aviso. altimetry.fr/duacs/). Absolute geostrophic velocity data were taken from the delayed time global product MADT (Maps of Absolute Dynamic Topography) given in the version "all sat merged". The data were extracted for the box $4-14^{\circ} \mathrm{N} / 35$ $20^{\circ} \mathrm{W}$ for the data period January 1993-September 2015 (processing date: 27 November 2015). 
The two main variability patterns of the surface circulation in the tropical North Atlantic can be described by the first complex EOF (empirical orthogonal function) mode of the zonal geostrophic velocity anomaly, where the real part of the EOF pattern mimics the meridional migration of the NECC and the imaginary pattern reflects the variability in its strength (Hormann et al., 2012). We applied an EOF analysis to the grid-point-wise filtered (mean and seasonal cycle removed and subsequently 2-year low-pass filtered) time series of Aviso zonal geostrophic velocity for the region given above in order to capture the interannual to decadal variability of the NECC/nNECC throughout the past decades. The first two EOF modes explained 23 and $14 \%$ of the total variance of the filtered time series and can be considered similarly to the real and imaginary patterns of the complex EOF as given in Hormann et al. (2012).

\subsection{Oxygen budget terms}

The oceanic oxygen distribution is governed on the one hand by oxygen-supplying processes such as physical transport and photosynthetic oxygen production and on the other hand by oxygen consumption driven by biological respiration and remineralisation of sinking organic matter (Karstensen et al., 2008; Brandt et al., 2015). In the ETNA, supply and consumption have not been in balance for the past decades (oxygen consumption was about 10-20\% larger than the supply processes), resulting in the aforementioned multidecadal oxygen trend (Brandt et al., 2010; Hahn et al., 2014; Karstensen et al., 2008). Mathematically, the oxygen budget is balanced when we allow for an oxygen tendency in addition to the oxygen supply and consumption terms. However, in order to investigate causes for the change in the oxygen trend from decadal to multi-decadal timescales (Brandt et al., 2015), temporal changes in the oxygen budget terms have to be analyzed. Following Hahn et al. (2014) and Brandt et al. (2015), we formulate the non-steady-state depth-dependent oxygen budget for the ETNA over the latitude range $6-14^{\circ} \mathrm{N}$ as

$$
[\underbrace{\partial_{t} \mathrm{O}_{2}}_{[1]}]^{(i)}=\underbrace{a O U R}_{[2]}+\underbrace{K_{\mathrm{e}} \partial_{y y} \mathrm{O}_{2}}_{[3]}+\underbrace{K_{\rho} \partial_{z z} \mathrm{O}_{2}}_{[4]}+[\underbrace{R_{\mathrm{O}_{2}}}_{[5]}]^{(i)},
$$

where the superscript on both sides of the equation denotes the time variation with respect either to the decadal $(i=1)$ or multi-decadal $(i=2)$ oxygen trend. The oxygen budget given by Eq. (1) describes the components contributing to the changes of the oxygen concentration, all of which are given in $\mu \mathrm{mol} \mathrm{kg} \mathrm{kg}^{-1} \mathrm{yr}^{-1}$. Term [1] $\left(\partial_{t} \mathrm{O}_{2}\right)$ on the left-hand side of the equation marks the observed temporal change of oxygen (oxygen tendency). While the multi-decadal oxygen trend was already considered in Hahn et al. (2014), the estimate of the decadal oxygen trend and its inclusion in the oxygen budget is a central part of this study (details of the calculation are given in Sect. 2.1). Term [2] $(a O U R)$ defines the oxygen consumption, which has been determined in Karstensen et al. (2008) following an approach that relates the apparent oxygen utilization (AOU) to water mass ages. Term [3] $\left(K_{e} \partial_{y y} \mathrm{O}_{2}\right)$ is the divergence of the meridional oxygen flux driven by eddy diffusion (Hahn et al., 2014). Term [4] $\left(K_{\rho} \partial_{z z} \mathrm{O}_{2}\right)$ is the divergence of the diapycnal oxygen flux due to turbulent mixing (Fischer et al., 2013). Term [5] includes all other oxygen supply mechanisms which could not be directly estimated from observational data: mean advection, zonal eddy diffusion and submesoscale processes. This term is calculated as the residual oxygen supply based on terms [1] to [4]. Here, we follow the argumentation given in Hahn et al. (2014) by considering the meridional structure of the eddy-driven meridional oxygen supply (term [3] in our Eq. 1) as well as the horizontal oxygen distribution (see also Fig. 10 therein); they argued for a major contribution of the mean zonal advection in the upper $350 \mathrm{~m}$, while zonal eddy diffusion and mean meridional advection have only a minor effect, and submesoscale processes are not assumed to affect the oxygen distribution well below the base of the mixed layer (Thomsen et al., 2016). Strictly, estimates of mean advection require the analysis of advective oxygen fluxes through the boundaries of a closed volume. Such measurements are however not available. Nevertheless, in Sect. 4.3, we present a rough estimate of the zonal advective flux across the $23^{\circ} \mathrm{W}$ section derived from data taken only along that section. Note that vertical advection, which was recently proposed in a model study (Pena-Izquierdo et al., 2015) to be present as part of two stacked subtropical cells, is not considered in the observationally based oxygen budget but will be discussed in Sect. 4.3 as well.

Given the data set in this study, a complete analysis of the temporal change of the consumption and supply terms, which ultimately are responsible for the change in the oxygen trend, cannot be performed due to insufficient data coverage and respective uncertainty reasons. Nevertheless, the decadal and multi-decadal oxygen trends $\left(\left[\partial_{t} \mathrm{O}_{2}\right]^{(1)}\right.$ and $\left.\left[\partial_{t} \mathrm{O}_{2}\right]^{(2)}\right)$ are applied separately in the oxygen budget. All other directly calculated terms (consumption, meridional eddy supply and diapycnal supply) are kept time invariant, while the residual oxygen supply is calculated for the respective time periods $\left(R_{\mathrm{O}_{2}}^{(1)}\right.$ and $R_{\mathrm{O}_{2}}^{(2)}$ ) based on the two oxygen trends. This ad hoc approach is used to particularly discuss zonal advection as a potential driver for the change in the oxygen trend. However, in Sect. 4.3, we also analyze and discuss the potential of all other ventilation terms in having driven the decadal oxygen trend.

\section{Results}

In this section, results will be shown from the combined analysis of moored, shipboard and float observations in the tropical Atlantic with a particular focus on the ETNA OMZ in order to investigate and quantify decadal changes of oxygen 

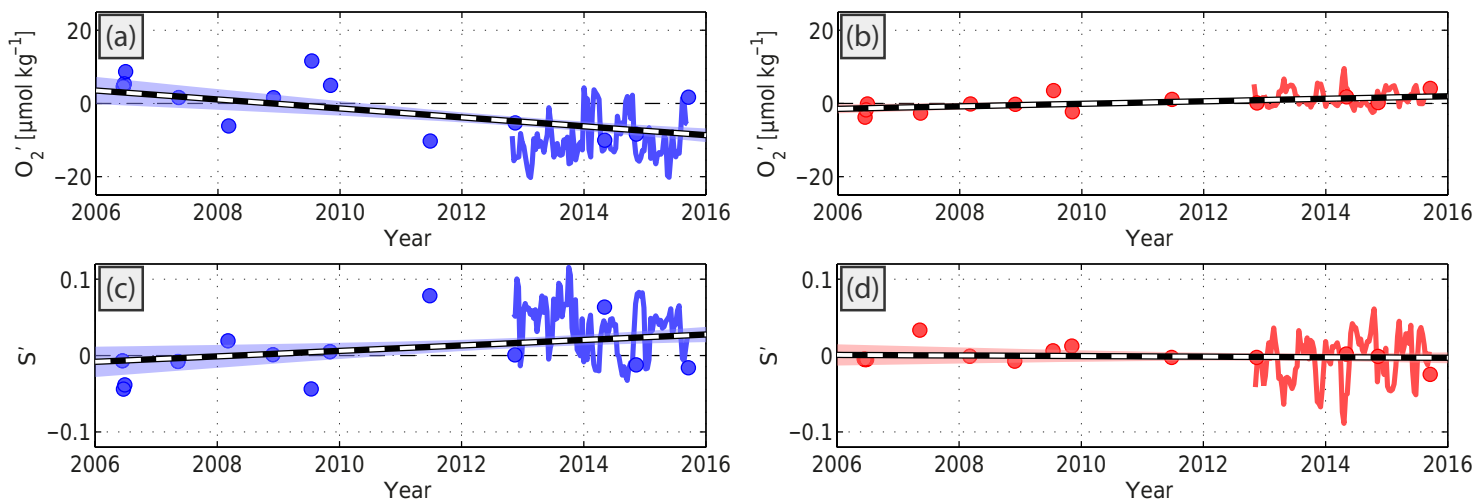

Figure 3. Oxygen (a and b) and salinity (c and d) anomaly time series from moored observations (solid line) at $11^{\circ} \mathrm{N}, 21^{\circ} \mathrm{W}$ and shipboard observations (dots) at $11^{\circ} \mathrm{N}, 23^{\circ} \mathrm{W}$. Panels (a) and (c) show averages between 200 and $400 \mathrm{~m}$. Panels (b) and (d) show averages between 500 and $800 \mathrm{~m}$. Black dashed lines show respective trends from combined moored and shipboard observations: (a) $-12.2 \pm 4.9 \mu \mathrm{mol} \mathrm{kg}{ }^{-1} \mathrm{decade}^{-1}$, (b) $3.4 \pm 1.6 \mu \mathrm{mol} \mathrm{kg}{ }^{-1} \mathrm{decade}^{-1}$, (c) $0.036 \pm 0.026 \mathrm{decade}^{-1}$ and (d) $-0.004 \pm 0.018 \mathrm{decade}^{-1}$.
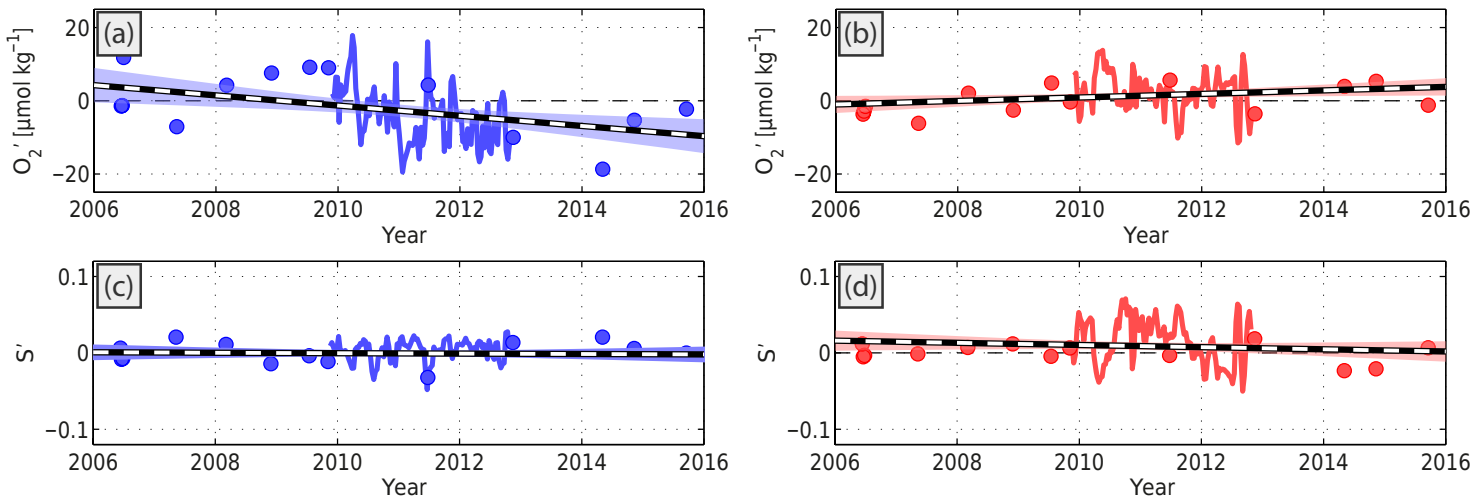

Figure 4. Oxygen (a and b) and salinity (c and d) anomaly time series from moored (solid line) and shipboard (dots) observations at $8^{\circ} \mathrm{N}, 23^{\circ} \mathrm{W}$. Panels (a) and (c) show averages between 200 and $400 \mathrm{~m}$. Panels (b) and (d) show averages between 500 and $800 \mathrm{~m}$. Black dashed lines show respective trends from combined moored and shipboard observations: (a) $-13.9 \pm 8.7 \mu \mathrm{mol} \mathrm{kg}-1 \mathrm{decade}^{-1}$, (b) $4.8 \pm 4.4 \mu \mathrm{mol} \mathrm{kg} \mathrm{decade}^{-1}$, (c) $-0.003 \pm 0.020 \mathrm{decade}^{-1}$ and (d) $-0.014 \pm 0.025 \mathrm{decade}^{-1}$.

as well as their correlation with changes in salinity. Changes in the velocity field were estimated based on repeat shipboard observations as well as satellite observations obtained mainly in the ETNA OMZ. Eventually, the oxygen budget of the ETNA was reanalyzed and revised from Hahn et al. (2014) with respect to both decadal and long-term oxygen changes.

\subsection{Mean state in the ETNA}

Given the mean $23^{\circ} \mathrm{W}$ section from shipboard observations, the core of the deep $\mathrm{OMZ}$ is located at $10^{\circ} \mathrm{N}$ and at $430 \mathrm{~m}$ depth with a minimum oxygen concentration of $41.6 \mu \mathrm{mol} \mathrm{kg}^{-1}$ (Fig. 2a). Between 100 and $250 \mathrm{~m}$, pronounced oxygen maxima at $5^{\circ} \mathrm{N}$ and $8-9^{\circ} \mathrm{N}$ coincide well with the core positions of the near-surface NECC and nNECC (Fig. 2c). Similar patterns could not be observed in the salinity distribution (Fig. 2b). However, the largest meridional salinity gradient was found in the $\mathrm{CW}$ layer (25.8-
$27.1 \mathrm{~kg} \mathrm{~m}^{-3}$ ) around $10^{\circ} \mathrm{N}$ and coincides with the northern edge of the near-surface eastward nNECC mirroring the transition zone from SACW to NACW, i.e., from low salinity close to the Equator to high salinity in the northern part of the section.

The transition from SAW to NAW is well reflected in the $\theta-S$ diagram (Fig. 2d), which shows $\theta-S$ characteristics for particular latitudes based on the mean hydrographic ship section along $23^{\circ} \mathrm{W}$ (Fig. $2 \mathrm{~b}$; temperature not shown). Following Rhein et al. (2005), a simple water mass analysis was evaluated taking into account NAW and SAW, whose characteristics were defined from MIMOC for their respective source areas $\left(25-30^{\circ} \mathrm{N} / 60-10^{\circ} \mathrm{W}\right.$ and $5^{\circ} \mathrm{S}-0^{\circ} \mathrm{N} / 40^{\circ} \mathrm{W}-$ $0^{\circ} \mathrm{E}$ ) (not shown). This revealed a strong spreading of SAW towards the north in the upper $300 \mathrm{~m}$ (UCW layer) with a SAW fraction of 0.9 close to the Cabo Verde archipelago at $13^{\circ} \mathrm{N}$. Below $300 \mathrm{~m}$ (LCW and intermediate water (IW) layers), fractions of SAW and NAW are similar, while NAW has 

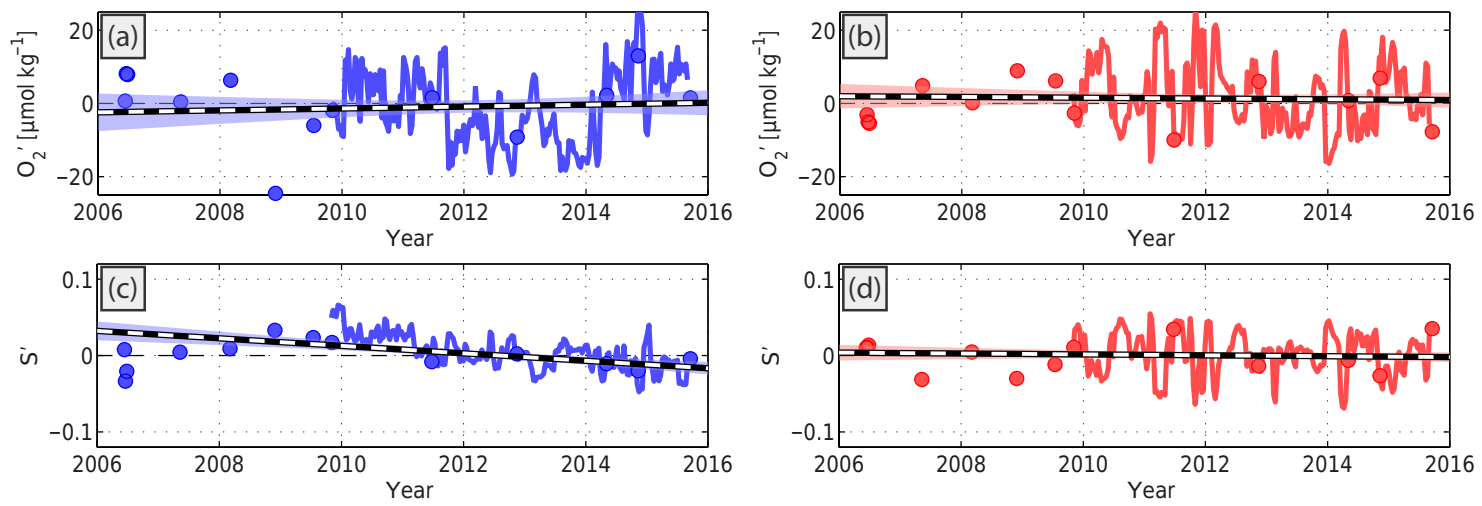

Figure 5. Oxygen (a and b) and salinity (c and d) anomaly time series from moored (solid line) and shipboard (dots) observations at $5^{\circ} \mathrm{N}, 23^{\circ} \mathrm{W}$. Panels (a) and (c) show averages between 200 and $400 \mathrm{~m}$. Panels (b) and (d) show averages between 500 and $800 \mathrm{~m}$. Black dashed lines show respective trends from combined moored and shipboard observations: (a) $2.6 \pm 7.8 \mu \mathrm{mol} \mathrm{kg} \mathrm{decade}^{-1}$, (b) $-1.1 \pm 4.9 \mu \mathrm{mol} \mathrm{kg}{ }^{-1} \mathrm{decade}^{-1}$, (c) $-0.049 \pm 0.019$ decade $^{-1}$ and (d) $-0.006 \pm 0.015 \mathrm{decade}^{-1}$.

Table 3. Oxygen and salinity tendencies (2006-2015) with the $95 \%$ confidence interval estimated for five different latitude boxes along $23^{\circ} \mathrm{W}$ and for the central water $(200-300 \mathrm{~m})$ and intermediate water $(500-800 \mathrm{~m})$ layers, respectively. Oxygen tendency was estimated from shipboard observations (cf. Fig. 6a) and salinity tendency was estimated from float observations (cf. Fig. 6c). Bold values define regimes with a significant decadal change.

\begin{tabular}{llrrrrr}
\hline & & $4-6^{\circ} \mathrm{N}$ & $6-8^{\circ} \mathrm{N}$ & $8-10^{\circ} \mathrm{N}$ & $10-12^{\circ} \mathrm{N}$ & $12-14^{\circ} \mathrm{N}$ \\
\hline $\begin{array}{l}\text { Central water } \\
(200-300 \mathrm{~m})\end{array}$ & $\begin{array}{l}\mathrm{O}_{2} \text { tendency } \\
\left(\mu \mathrm{mol} \mathrm{kg}^{-1} \mathrm{decade}^{-1}\right)\end{array}$ & $2.4 \pm 8.8$ & $\mathbf{- 9 . 9} \pm \mathbf{8 . 2}$ & $\mathbf{- 1 1 . 1} \pm \mathbf{8 . 3}$ & $\mathbf{- 1 1 . 4} \pm \mathbf{5 . 9}$ & $-4.1 \pm 5.5$ \\
\cline { 2 - 6 } & $\begin{array}{l}S \text { tendency } \\
\left(10^{-2} \text { decade }\right.\end{array}$ & $\mathbf{1 . 3} \pm \mathbf{0 . 3}$ & $\mathbf{1 . 0} \pm \mathbf{0 . 4}$ & $0.6 \pm 0.7$ & $\mathbf{2 . 7} \pm \mathbf{1 . 1}$ & $\mathbf{2 . 4} \pm \mathbf{2 . 3}$ \\
\hline $\begin{array}{l}\text { Intermediate water } \\
(500-800 \mathrm{~m})\end{array}$ & $\begin{array}{l}\mathrm{O}_{2} \text { tendency } \\
\left(\mu \text { mol kg }^{-1} \text { decade }^{-1}\right)\end{array}$ & $1.3 \pm 5.3$ & $\mathbf{4 . 0} \pm \mathbf{3 . 6}$ & $\mathbf{5 . 8} \pm \mathbf{3 . 1}$ & $\mathbf{4 . 1} \pm \mathbf{1 . 9}$ & $\mathbf{4 . 5} \pm \mathbf{2 . 7}$ \\
\cline { 2 - 6 } & $\begin{array}{l}S \text { tendency } \\
\left(10^{-2} \text { decade }\right.\end{array}$ & $\mathbf{1 . 6} \pm \mathbf{0 . 5}$ & $0.4 \pm 0.6$ & $\mathbf{- 2 . 4} \pm \mathbf{0 . 9}$ & $\mathbf{- 1 . 3} \pm \mathbf{1 . 1}$ & $-0.2 \pm 1.5$ \\
\hline
\end{tabular}

its southernmost extension at about $550 \mathrm{~m}$ with a fraction of 0.2 at $6^{\circ} \mathrm{N}$.

\subsection{Interannual variability and decadal change of oxygen and salinity}

In this section, we present the temporal variability of oxygen and salinity obtained from shipboard, moored and float observations of the most recent decade and investigate the correlation between these two variables. Decadal trends were derived at the aforementioned mooring positions as well as for the $23^{\circ} \mathrm{W}$ section between 4 and $14^{\circ} \mathrm{N}$.

While the mean $23^{\circ} \mathrm{W}$ oxygen section shows a minimum oxygen concentration of $41.6 \mu \mathrm{mol} \mathrm{kg}-1$ (see Sect. 3.1), individual CTD profiles taken in the core of the deep OMZ between 300 and $700 \mathrm{~m}$ throughout the past decade regularly reached minimum oxygen concentrations well below $40 \mu \mathrm{mol} \mathrm{kg}^{-1}$ (see also Stramma et al., 2009). An absolute minimum of $36.5 \mu \mathrm{mol} \mathrm{kg}^{-1}$ was observed at $12.5^{\circ} \mathrm{N}, 23^{\circ} \mathrm{W}$ at $410 \mathrm{~m}$ during the RV Maria S. Merian cruise MSM22 in November 2012.

The combined analysis of shipboard and moored observations (for details, see Sect. 2.2) revealed a remarkable oxygen change in the ETNA OMZ at latitudes 11 and $8^{\circ} \mathrm{N}$ throughout the past decade (Figs. 3a, b and 4a, b). Oxygen strongly decreased in the upper depth layer (200-400 m) and increased below (500-800 m), with salinity partly showing opposite trends (Figs. 3c, d and 4c, d). Superimposed on this decadal change, additional variability on intraseasonal to interannual timescales was observed. At $5^{\circ} \mathrm{N}$, intraseasonal to interannual oxygen variability was the dominant signal (Fig. 5), and a decadal oxygen change could not be observed for this latitude. Note that besides the energetic salinity variability on intraseasonal to interannual timescales, the combination of shipboard and moored observations also suggests salinity fluctuations on a decade-long timescale in the upper depth layer (200-400 m; Fig. 5c). 

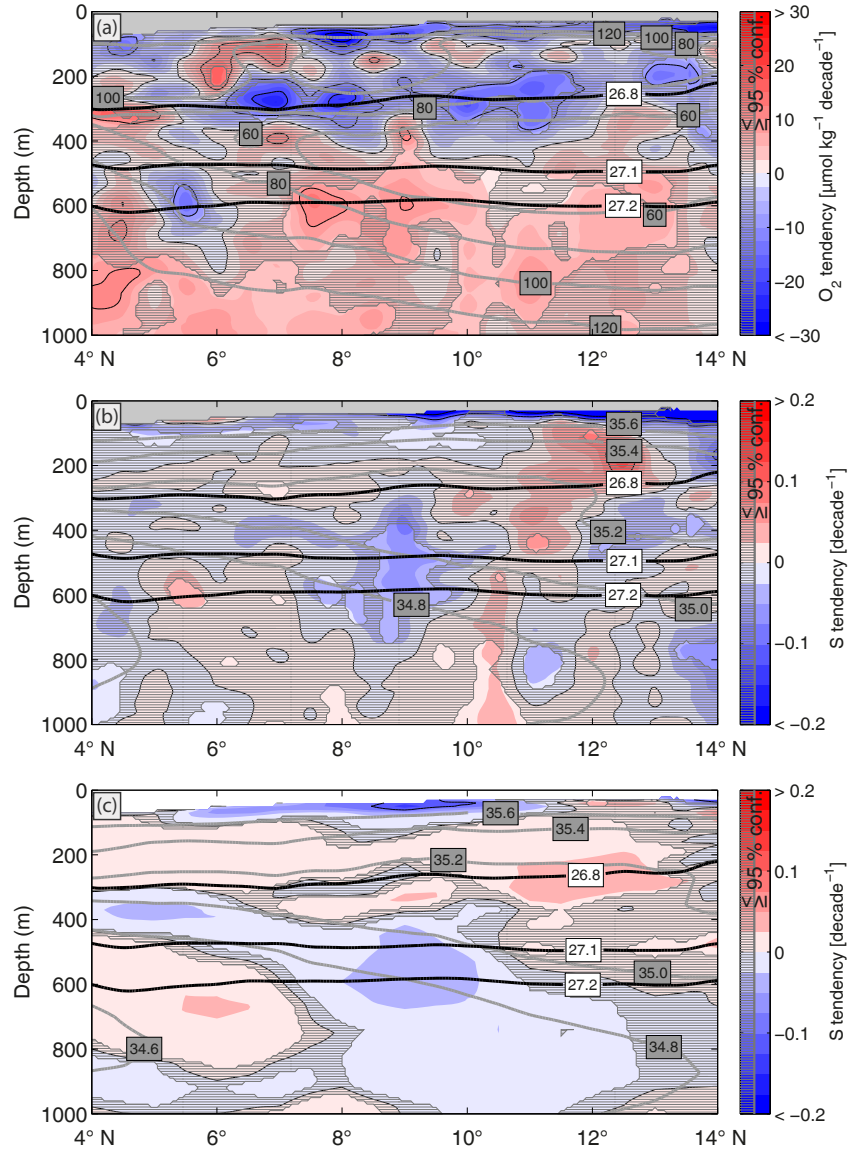

Figure 6. Depth-latitude section of the linear trend (filled contours) of $(\mathbf{a})$ oxygen and $(\mathbf{b}, \mathbf{c})$ salinity in the ETNA along $23^{\circ} \mathrm{W}$. Panels (a) and (b) were calculated from repeat shipboard observations in the period 2006-2015. Panel (c) was calculated from Argo float observations in the period 2006-2015. All calculations were done on density surfaces with subsequent projection onto depth surfaces. Gray-hatched areas mark non-significant regimes with respect to $95 \%$ confidence. Mean fields of oxygen and salinity, respectively, are given as gray contours. Thick black contours define isopycnal surfaces $26.8,27.1$ and $27.2 \mathrm{~kg} \mathrm{~m}^{-3}$.

Based on shipboard observations, the $23^{\circ} \mathrm{W}$ section of decadal oxygen tendency for the period 2006-2015 (Fig. 6a) revealed coherent large-scale patterns of oxygen decrease and oxygen increase. Even though only a part of the local trends is statistically significant, the spatial coherence of the trends suggests robust trend patterns. Note also that significant patterns were larger than twice the smoothing and interpolation scale of the individual ship sections. A strongly decreasing oxygen concentration with up to $-20 \mu \mathrm{mol} \mathrm{kg} \mathrm{decade}^{-1}$ was found in the latitude range from 6 to $14^{\circ} \mathrm{N}$ and at a depth range 200 to $400 \mathrm{~m}$ (on average $-5.9 \pm 3.5 \mu \mathrm{mol} \mathrm{kg}{ }^{-1}$ decade $^{-1}$ ). Between 400 and $1000 \mathrm{~m}$, oxygen was found to increase with an average magnitude of about $4.0 \pm 1.6 \mu \mathrm{mol} \mathrm{kg}{ }^{-1}$ decade $^{-1}$ between 6 and $14^{\circ} \mathrm{N}$. Locally, a significant oxygen increase was observed
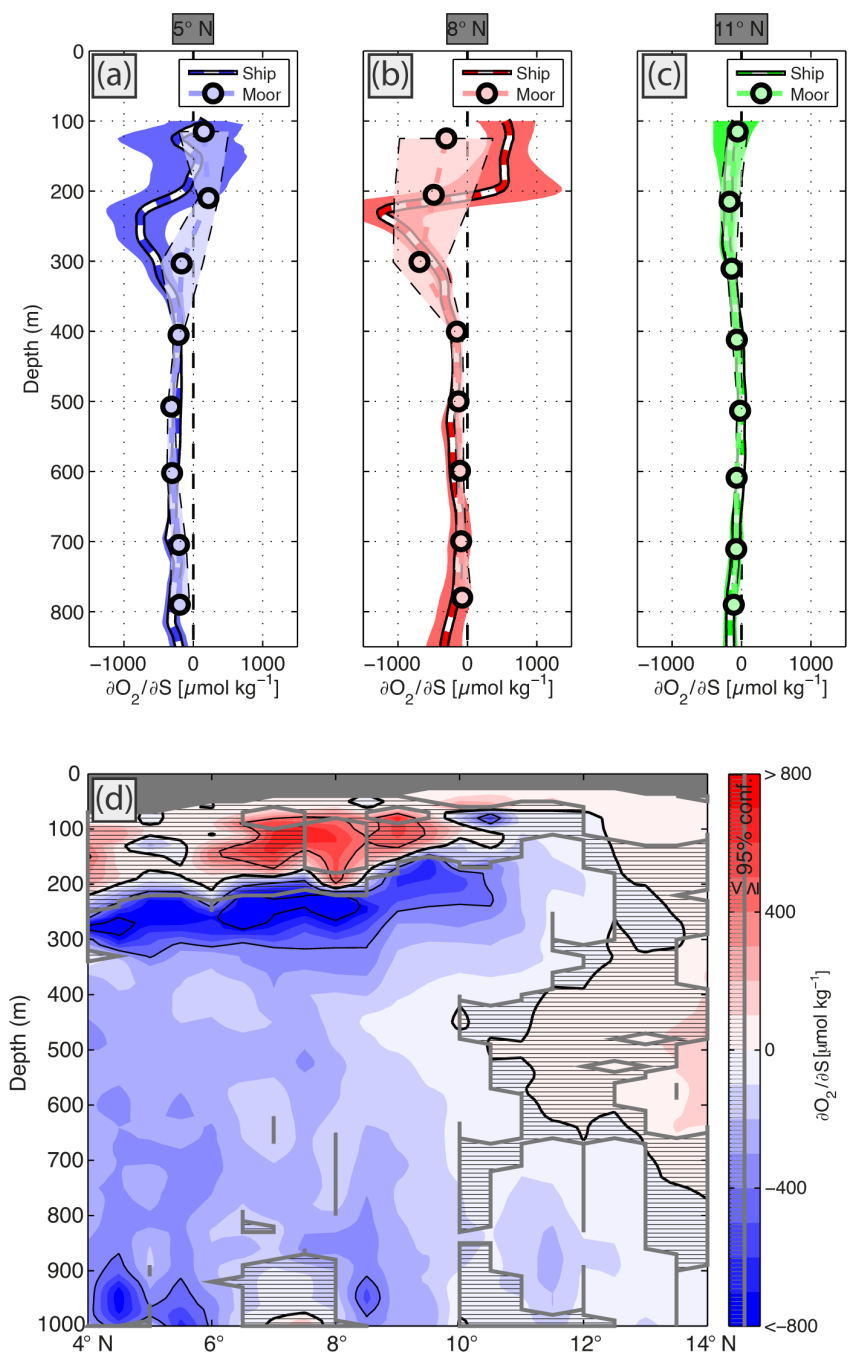

Figure 7. Vertical profiles of the slopes of the linear fits of oxygen against salinity with $95 \%$ confidence intervals for moored (whitecolored dashed line) and shipboard observations (colored dots) at positions (a) $5^{\circ} \mathrm{N}, 23^{\circ} \mathrm{W}$, (b) $8^{\circ} \mathrm{N}, 23^{\circ} \mathrm{W}$ and (c) $11^{\circ} \mathrm{N}, 21^{\circ} \mathrm{W}$. (d) Depth-latitude section (along $23^{\circ} \mathrm{W}$ ) of the slope of the linear fit of oxygen against salinity (filled contours). Gray-hatched areas define non-significant regimes with respect to $95 \%$ confidence.

below the OMZ core depth at 500-700 $\mathrm{m}$ in the latitude range $7-13^{\circ} \mathrm{N}$ as well as at $800-1000 \mathrm{~m}$ in the latitude range 4$11^{\circ} \mathrm{N}$. Box averages of decadal oxygen tendency for selected latitude and depth ranges together with their $95 \%$ confidence estimates are presented in Table 3.

Shipboard observations mainly showed no significant decadal salinity tendency for the period 2006-2015 (Fig. 6b). In a similar approach, we additionally calculated the decadal salinity tendency from Argo float observations (with reference to the seasonal cycle of MIMOC) for the same time period (Fig. 6c). This resulted in a more robust estimate (see Table 3 for corresponding box averages) showing a salinity increase over almost the whole latitude range at the depth 

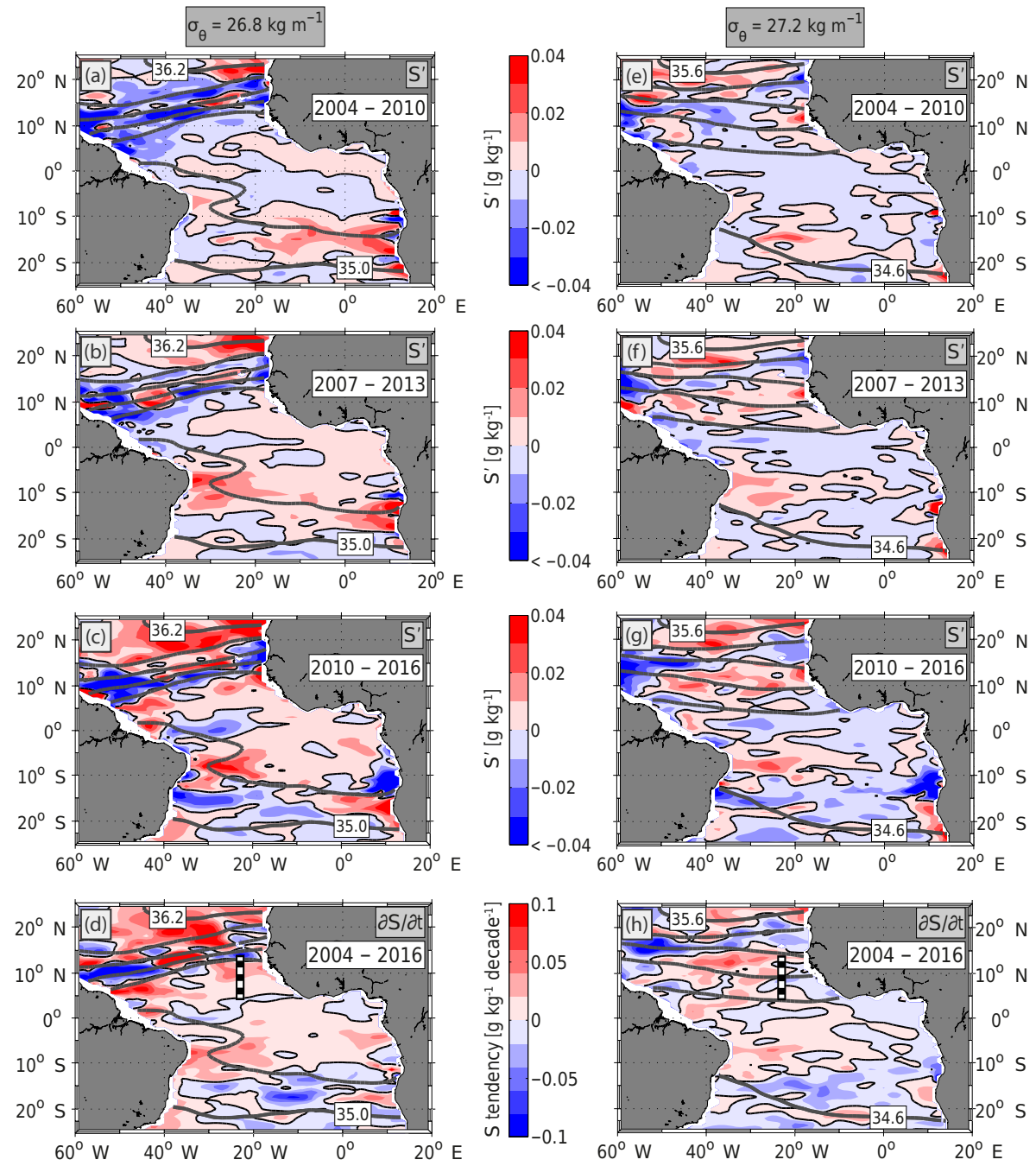

Figure 8. Salinity anomalies (filled contours) in the tropical Atlantic at the isopycnal surface $26.8 \mathrm{~kg} \mathrm{~m}^{-3}$ from Argo float observations for the period (a) 2004-2010, (b) 2007-2013 and (c) 2010-2016. (d) Salinity trend (filled contours) calculated from all salinity anomalies at isopycnal surface $26.8 \mathrm{~kg} \mathrm{~m}^{-3}$ between 2004 and 2016 . The black-white dashed line marks the $23^{\circ} \mathrm{W}$ section between 4 and $14^{\circ} \mathrm{N}$ for reference. Gray contours in panels (a) to (d) define the mean salinity distribution. Panels (e) to (h) are same as (a) to (d) but for isopycnal surface $27.2 \mathrm{~kg} \mathrm{~m}^{-3}$.

range of about 100 to $350 \mathrm{~m}$. Between 400 and $1000 \mathrm{~m}$, salinity decreased between about 7 and $11^{\circ} \mathrm{N}$ as well as increased between about 4 and $7^{\circ} \mathrm{N}$.

Variability in physical ventilation processes may drive coherent changes in different tracers such as salinity or oxygen. Based on shipboard and moored observations, we calculated the correlation between oxygen and salinity (see Sect. 2.1 and 2.2 for details of the calculation) and identified significant regimes along $23^{\circ} \mathrm{W}$ (Fig. 7). A significant negative correlation was found below the deep oxycline and south of the OMZ core (average slope $\partial \mathrm{O}_{2} / \partial S=$ $-255 \pm 140 \mu \mathrm{mol} \mathrm{kg}^{-1}$ ) - a regime with a pronounced positive gradient in salinity and negative gradient in oxygen on isopycnal surfaces in the northeast direction (cf. Fig. 2 in this study; Kirchner et al., 2009; Pena-Izquierdo et al., 2015).
North of the OMZ core, the correlation is positive, which agrees well with the positive oxygen and salinity gradient in northward direction in this regime. Note that above the deep oxycline (upper $300 \mathrm{~m}$ ) the correlations obtained from moored and shipboard observations partly disagree with each other, which might be due to generally larger variability and the different time periods covered by both observational data sets.

The box averages (Table 3 ) for selected latitude and depth ranges show that significant decadal changes both in oxygen and salinity were found in the $\mathrm{CW}$ layer at $6-8^{\circ} \mathrm{N}$ and 10 $12^{\circ} \mathrm{N}$ as well as in the IW layer between 8 and $12^{\circ} \mathrm{N}$. All significant tendencies were inversely related to each other and agreed well with regimes of significant anticorrelation of oxygen and salinity (Fig. 7). 

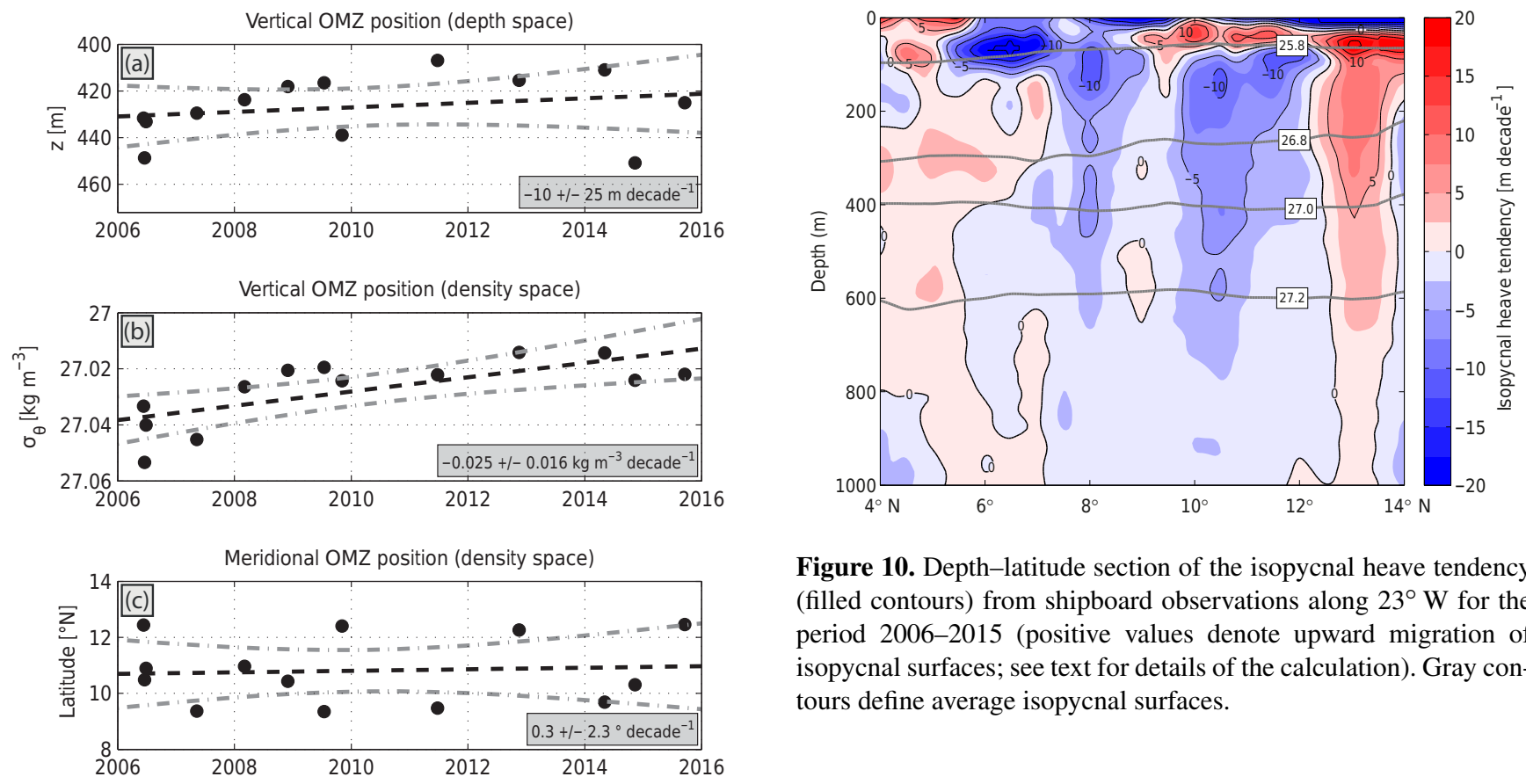

Figure 10. Depth-latitude section of the isopycnal heave tendency (filled contours) from shipboard observations along $23^{\circ} \mathrm{W}$ for the period 2006-2015 (positive values denote upward migration of isopycnal surfaces; see text for details of the calculation). Gray contours define average isopycnal surfaces.

Figure 9. Time series (black dots) of the OMZ core position (defined as the $5 \%$ area of lowest oxygen) obtained from individual ship sections along $23^{\circ} \mathrm{W}$. Panels (a) and (b) show the vertical position in depth and density space. Panel (c) shows the meridional position in density space (that is similar in depth space). The black dashed line shows the respective linear trend with the $95 \%$ confidence band (gray dashed-dotted lines).

For the two respective depth layers, changes in salinity over the past decade (2004-2016) were further investigated for the whole tropical Atlantic by analyzing Argo float observations for two characteristic density surfaces (26.8 and $27.2 \mathrm{~kg} \mathrm{~m}^{-3}$ ) (see Sect. 2.4 for details). At density layer $26.8 \mathrm{~kg} \mathrm{~m}^{-3}$, salinity generally increased between $10^{\circ} \mathrm{S}$ and $10^{\circ} \mathrm{N}$ (Fig. 8 a to d). Here, a propagation of positive salinity anomalies was observed from the tropical South Atlantic toward the north and the western boundary throughout the past decade (cf. Kolodziejczyk et al., 2014 for shallower depths). Further north, a negative salinity trend was found between about 10 and $20^{\circ} \mathrm{N}$, and a positive trend was found north of $20^{\circ} \mathrm{N}$. At density layer $27.2 \mathrm{~kg} \mathrm{~m}^{-3}$, the northward propagation of positive salinity anomalies from the tropical South Atlantic was less pronounced (Fig. 8e to h). A generally positive decadal salinity tendency was found for this density layer between about $10^{\circ} \mathrm{S}$ and $10^{\circ} \mathrm{N}$, but regionally negative salinity tendencies were found as well, e.g., salinity decreased along $23^{\circ} \mathrm{W}$ between about 7 and $11^{\circ} \mathrm{N}$ (cf. Figs. $6 \mathrm{c}$ and $8 \mathrm{~h}$ ).

Changes in the spatial oxygen distribution go along with changes in the OMZ core position. Here, the vertical and meridional position of the OMZ core was estimated for every ship section by taking the center of the $5 \%$ area of lowest oxygen (the $1 \%$ area gave similar results) found between 8

and $14^{\circ} \mathrm{N}$ in depth $(400-460 \mathrm{~m})$ and density space $(27.00-$ $27.06 \mathrm{~kg} \mathrm{~m}^{-3}$ ), respectively. Decadal trends with $95 \%$ confidence were then calculated for depth, density and latitude of the OMZ core in order to derive the vertical and meridional migration of the OMZ core (Fig. 9). We found a migration of the OMZ core position in density space toward lighter water $\left(-0.03 \pm 0.02 \mathrm{~kg} \mathrm{~m}^{-3} \mathrm{decade}^{-1}\right)$, whereas no significant upward migration in depth space could be shown $\left(-10 \pm 25 \mathrm{~m} \mathrm{decade}^{-1}\right)$ from this estimate. Note that by considering the vertical displacement of density surfaces throughout this decade, a significant upward migration of the OMZ core could be shown in depth space as well (details are given in Sect. 4.1). No significant meridional migration of the OMZ core was observed both in depth and density space (about $0.3 \pm 2.3^{\circ}$ decade $^{-1}$ ).

The migration of the OMZ core in density space might be due to a decadal change in the depth of the density surfaces (isopycnal heave tendency; Fig. 10). The isopycnal heave tendency was derived from all hydrographic shipboard observations carried out along $23^{\circ} \mathrm{W}$ between 2006 to 2015. Density surfaces deepened (stratification increased) at latitudes $7-12^{\circ} \mathrm{N}$ below $100 \mathrm{~m}\left(3.2 \pm 0.4 \mathrm{~m} \mathrm{decade}^{-1}\right.$ at the OMZ core depth) and shoaled north and south of this latitude band (stratification decreased).

\subsection{Circulation changes in the ETNA}

A change in the large-scale circulation is a possible source for the decadal changes in oxygen and salinity presented in the previous section. Such circulation changes would likely precede changes in the discussed tracers (cf. Brandt et al., 2012) and several decade-long observations would be necessary in order to attribute such a relationship. Here, we are 

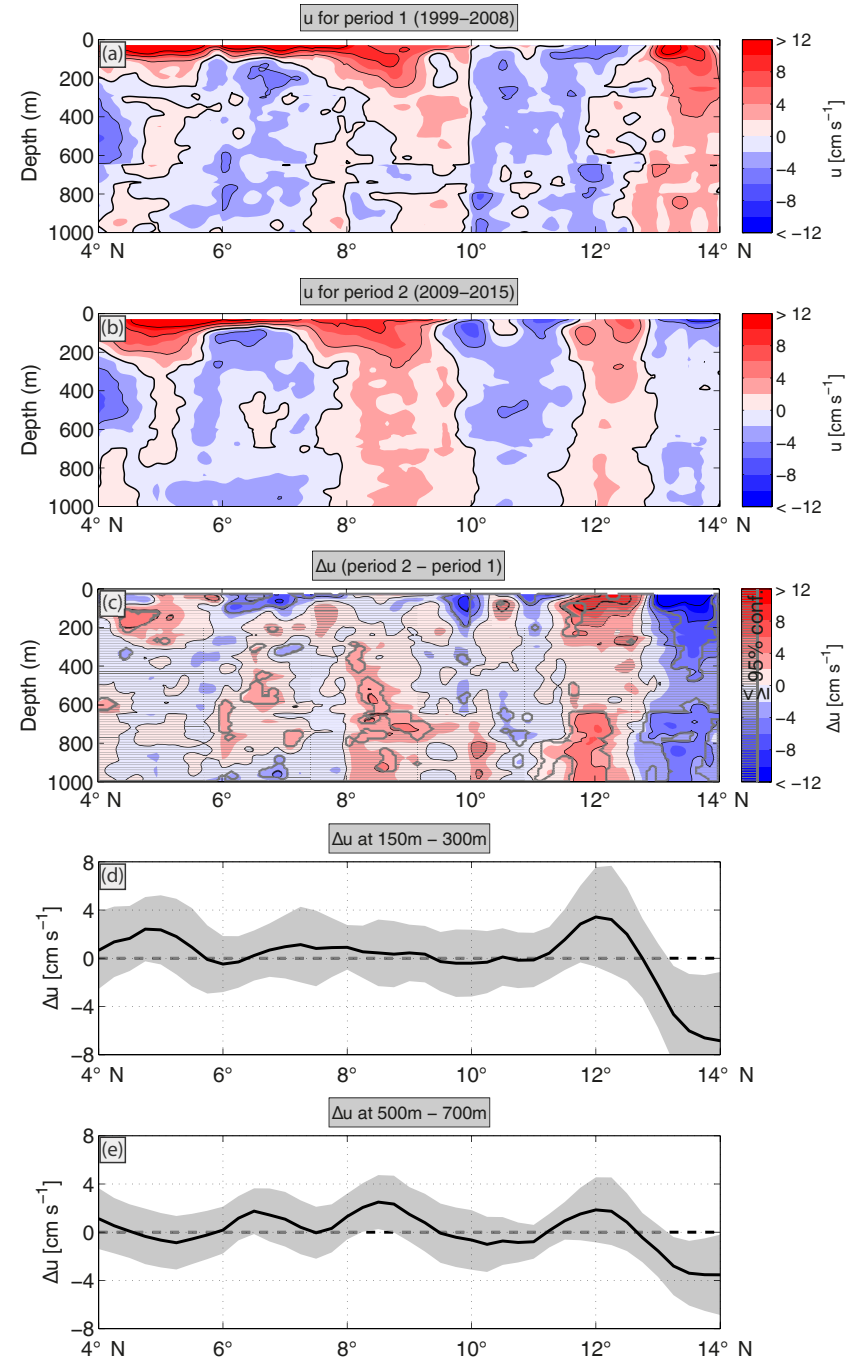

Figure 11. Depth-latitude section of mean zonal velocity from shipboard observations along $23^{\circ} \mathrm{W}$ for (a) 1999-2008 and (b) 20092015. (c) Depth-latitude section of the difference of zonal velocity between the aforementioned two periods ((b) minus (a)). Gray hatching defines non-significant regimes with respect to $95 \%$ confidence. The interval of the black solid velocity contour lines in (a) to (c) is $4 \mathrm{~cm} \mathrm{~s}^{-1}$. (d) Vertical average of (c) for the depth range 150-300 m (black line). The gray-shaded area marks the $95 \%$ confidence band. Panel (e) is the same as (d) but for the depth range 500-700 m.

far away from quantitatively linking circulation variability to decadal changes in oxygen and salinity. Nevertheless, in the following, we present observed changes in the circulation in order to discuss the potential impact on the hydrographic and oxygen distribution in the ETNA.

The isopycnal heave tendency (Fig. 10) showed a change in the stratification around the OMZ, which points to a change in the geostrophic circulation. Repeat shipboard ADCP and hydrographic observations were subsequently used in order to investigate the decadal change in the zonal

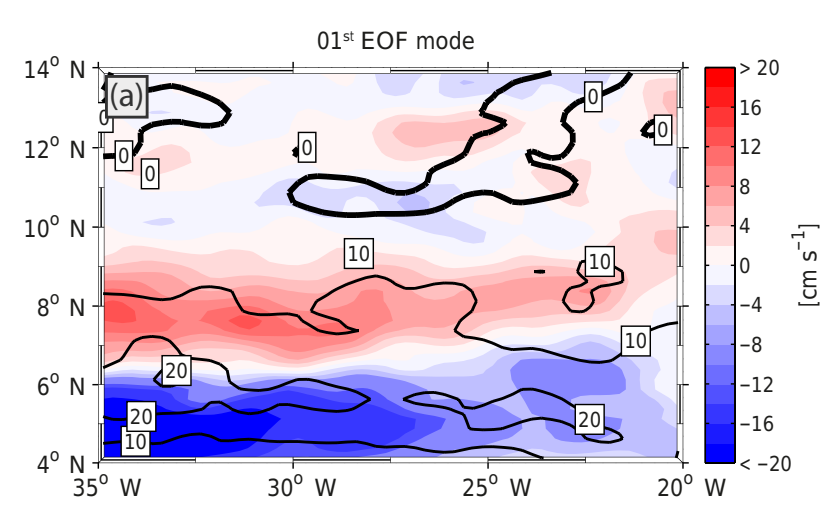

$02^{\text {nd }}$ EOF mode
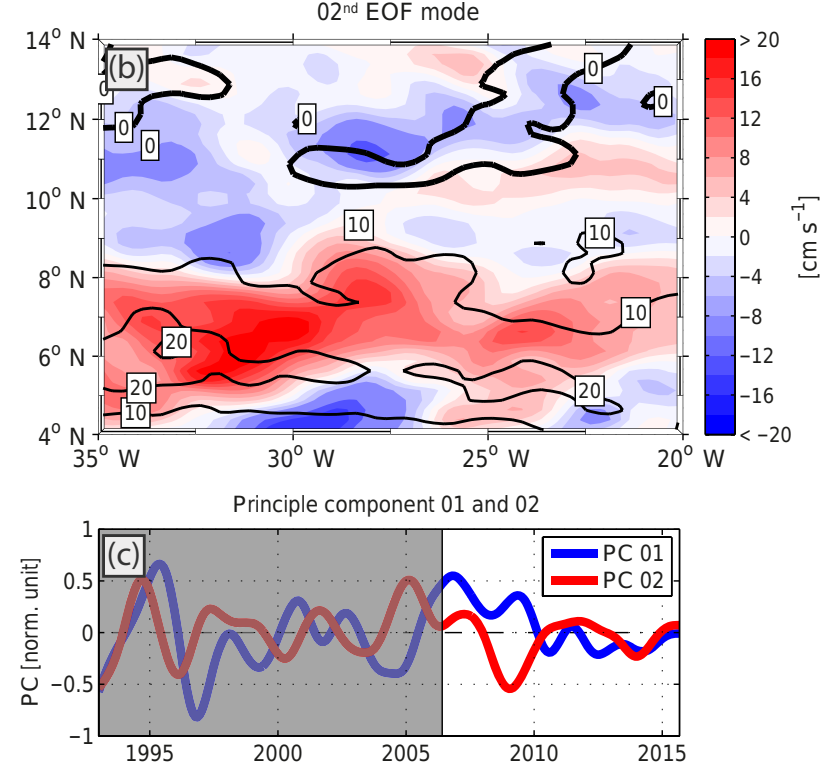

Reconstructed u from EOF modes 01 and 02

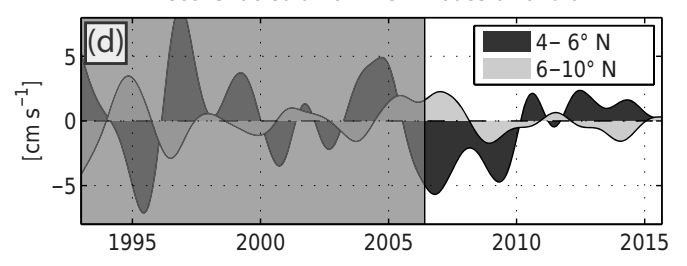

Figure 12. (a) First and (b) second EOF modes of the filtered (mean and seasonal cycle removed and subsequently 2-year lowpass filtered; see text for details) surface zonal geostrophic velocity from Aviso (filled contours; positive eastward) for the tropical North Atlantic. Black contours define isolines of mean surface zonal geostrophic velocity from Aviso in $\mathrm{cm} \mathrm{s}^{-1}$ (positive eastward). (c) Principle components 01 and 02 corresponding to the first two EOF modes given in (a) and (b). (d) Time series of eastward velocity (averaged between 35 and $20^{\circ} \mathrm{W}$ for the latitude bands 4-6 and 6$10^{\circ} \mathrm{N}$ ) reconstructed from the first two EOF modes, given in (a) and (b), and corresponding principle components in (c). White boxes (right segments of panels $\mathbf{c}$ and d) mark the time period (20062015) of shipboard observations used for the estimate of the decadal oxygen and salinity trend section in Fig. 6 (cf. Table 1). Gray boxes (left segments) mark the time period before. 
velocity. Zonal velocity sections derived from a geostrophic approach as well as from shipboard ADCP observations were very similar, with both reasonably representing the winddriven near-surface currents (NECC and nNECC) as well as the LAZJs at depth. In the following, only shipboard ADCP observations are shown.

Zonal velocity from shipboard ADCP observations was estimated along $23^{\circ} \mathrm{W}$ as an average for the periods 1999-2008 and 2009-2015 (Fig. 11a and b) to determine the decadal change. A one-tailed $t$ test (directional hypothesis) was applied to evaluate the significance (95\% confidence) of the difference of the means for the two periods (Fig. 11c to e). Zonal velocity did not change for most parts of the section (80-90\%), but two latitudinal regimes were identified with significant difference between both periods. First, eastward and westward currents were observed at latitudes $12-13^{\circ} \mathrm{N}$ and $13-14^{\circ} \mathrm{N}$ over the whole depth range in the latter period, which was reversed in the first period. Second, the eastward jet, centered at about $9^{\circ} \mathrm{N}$, widened at depths below about $300 \mathrm{~m}$ from the first to the latter period, going along with a narrowing of the westward jet north of it.

In order to investigate the variability of the NECC/nNECC, we applied an EOF analysis to the Aviso altimetry-based surface geostrophic velocity observations given for the region $\left(35-20^{\circ} \mathrm{W}, 4-10^{\circ} \mathrm{N}\right.$ ) (for details, see Sect. 2.5). Considering the results in relation to the mean zonal geostrophic velocity, the first EOF describes maximum (out-of-phase) variability of the zonal geostrophic velocity north and south of the NECC core latitude at about $6^{\circ} \mathrm{N}$ (capturing a meridional migration of the NECC; Fig. 12a), whereas the second EOF describes maximum variability at about the core latitude of the NECC (capturing an intensification or weakening of the NECC, Fig. 12b). The principal component (PC) corresponding to the first EOF mode (first and second PCs are shown in Fig. 12c) declined throughout the past decade, which points to a southward migration of the NECC. The PC corresponding to the second EOF mode revealed only shorter-term (interannual) variability in the strength of the NECC. Reconstructing the zonal geostrophic velocity anomaly out of the first two EOFs and the corresponding PCs with subsequent averaging in the boxes $\left(35-20^{\circ} \mathrm{W}, 4-6^{\circ} \mathrm{N}\right.$ and $\left.35-20^{\circ} \mathrm{W}, 6-10^{\circ} \mathrm{N}\right)$ (Fig. 12d) showed that eastward velocity increased in the latitude band $4-6^{\circ} \mathrm{N}$ and decreased in the latitude band $6-10^{\circ} \mathrm{N}$ throughout the past decade.

\subsection{Decadal and long-term changes in the oxygen budget of the ETNA OMZ}

The multi-decadal oxygen trend (1972-2008) was discussed in the oxygen budget of the ETNA OMZ in Hahn et al. (2014) (see also Sect. 2.6). Here, the depth profile of the decadal oxygen trend observed for the period 2006-2015 (average between 6 and $14^{\circ} \mathrm{N}$ of the $23^{\circ} \mathrm{W}$ section; cf. Fig. 6a) was additionally included in order to discuss temporal changes in the oxygen budget (Fig. 13). The decadal oxygen trend showed an oxygen decrease/increase in the depth range 150$400 \mathrm{~m} / 400-800 \mathrm{~m}$, whereas during the period 1972-2008 an oxygen decrease was found over the whole depth range (here shown for 130-800 m). Other terms in the oxygen budget, namely oxygen consumption, meridional eddy supply and diapycnal supply were calculated as described in Brandt et al. (2015) as well as in corresponding studies of Karstensen et al. (2008), Fischer et al. (2013) and Hahn et al. (2014).

The vertical profiles of the decadal (2006-2015) and multi-decadal (1972-2008) oxygen trend were independently treated in the oxygen budget (Fig. 13). Other terms such as consumption, meridional eddy supply and diapycnal supply were kept time invariant. The change in the oxygen trend between the two periods was projected onto the residual oxygen supply (cf. Eq. 1), which is mainly attributed to the zonal advective supply due to zonal jets ventilating the eastern basin from the oxygenated western boundary (Brandt et al., 2015). At first glance, this projection seems like a rather strict assumption, though the temporal variability in the oxygen budget shall be discussed exemplarily using the residual supply without loss of generality. However, in Sect. 4.3, we will discuss in detail the potential of all ventilation terms in their contribution to the decadal oxygen change. As will be shown, the zonal advective oxygen supply is the most probable budget term responsible for the observed oxygen changes.

According to the two oxygen trend profiles, two different residual supply profiles resulted for the periods 1972-2008 and 2006-2015, respectively. Both residuals show a strong zonal advective supply in the upper $350 \mathrm{~m}$, including a steep drop-off and subsequently a rather homogeneous supply between 400 and $800 \mathrm{~m}$. In comparison to the earlier period (1972-2008), the residual supply in the depth range below $400 \mathrm{~m}$ homogeneously doubled in magnitude for the recent decade (2006-2015). The strong zonal advective supply in the upper $350 \mathrm{~m}$ only changed marginally and shifted to a slightly shallower depth in the past decade (2006-2015) being barely significant with regard to the large confidence intervals.

\section{Discussion}

\subsection{Decadal oxygen and salinity changes in the ETNA}

For the period 2006-2015, shipboard and moored observations in the ETNA along $23^{\circ} \mathrm{W}$ revealed a decadal change of oxygen between 6 and $14^{\circ} \mathrm{N}$ with a strong decrease (Fig. 6a) in the depth of the deep oxycline between 200 and $400 \mathrm{~m}$ $\left(-5.9 \pm 3.5 \mu \mathrm{mol} \mathrm{kg} \mathrm{decade}^{-1}\right)$ and a large-scale increase below $\left(4.0 \pm 1.6 \mu \mathrm{mol} \mathrm{kg}{ }^{-1}\right.$ decade $\left.^{-1}\right)$. This vertically oriented dipole pattern is centered approximately at the depth of the OMZ core and is consistent with the observed upward migration of the OMZ core in density and depth space 
throughout the past decade (Fig. 9). Strictly, shipboard observations revealed a significant shoaling of the OMZ core only in density space. However, the average vertical migration in density space $\left(-0.03 \pm 0.02 \mathrm{~kg} \mathrm{~m}^{-3}\right.$ decade $\left.^{-1}\right)$ was too large to be compensated by the isopycnal heave (Fig. 10; $3.2 \pm 0.4 \mathrm{~m} \mathrm{decade}^{-1}$ ) when considering the observed mean background vertical density gradient of about $1.2 \times 10^{-3} \mathrm{~kg} \mathrm{~m}^{-3}$ per $\mathrm{m}$ (not shown). By taking these estimates into account, we additionally expect that an upward migration of the OMZ core has happened in depth space as well by about $-22 \pm 17 \mathrm{~m} \mathrm{decade}^{-1}$.

While the decadal oxygen change is characterized by a vertical dipole pattern, the multi-decadal oxygen trend (1972-2013), analyzed for the tropical and subtropical Atlantic along $23^{\circ} \mathrm{W}$ by Brandt et al. (2015), shows a largescale moderate oxygen decrease for the whole ETNA OMZ regime. Maximum rates of about $-5 \mu \mathrm{mol} \mathrm{kg}{ }^{-1}$ decade $^{-1}$ therein were substantially smaller than maximum rates of oxygen decrease $\left(-20 \mu \mathrm{mol} \mathrm{kg}{ }^{-1}\right.$ decade $\left.^{-1}\right)$ found in this study for the recent decade (Fig. 6a). At the OMZ core depth and below, observed opposite oxygen trends on decadal and multi-decadal timescales suggest that different mechanisms may act in parallel and drive these oxygen changes. Note that the local maximum of the multi-decadal oxygen decrease (Brandt et al., 2015) is at around $20^{\circ} \mathrm{N}$ and $450 \mathrm{~m}$ $\left(-7 \mu \mathrm{mol} \mathrm{kg} \mathrm{decade}^{-1}\right)$, indicating a northward shift of the ETNA OMZ likely associated with a similar shift in the circulation pattern. In contrast, the observed upward migration of the ETNA OMZ in the recent decade might be understood as the consequence of a decreased ventilation in the upper $400 \mathrm{~m}$ and an increased ventilation below.

Oxygen variability was strongly related to salinity variability in the ETNA at the depth of the deep oxycline and below (Fig. 7). Both variables were found to be significantly negatively correlated south of the OMZ core, while a weak positive correlation was found north of it. This reflects the supply of the OMZ with fresher SAW from the Southern Hemisphere as well as saltier NAW from the Northern Hemisphere via different ventilation pathways (Brandt et al., 2015; Pena-Izquierdo et al., 2015; Kirchner et al., 2009). Nevertheless, we cannot exclusively link decadal changes in hydrography to decadal changes in the water mass composition in order to explain changes in oxygen, as source waters may change their $\theta-S$ characteristics as well. Instead, a straightforward approach is the analysis of salinity variability to detect both a change in the ventilation as well as a change in the source water masses.

The significant decadal change in oxygen along $23^{\circ} \mathrm{W}$ was inversely related to a significant decadal change in salinity in the CW and IW layers (below $200 \mathrm{~m}$ ) south of the OMZ core position (Fig. 6 and Table 3). In the deep oxycline, the strong oxygen decrease was accompanied by a salinity increase, whereas below $400 \mathrm{~m}$ the large-scale oxygen increase was accompanied partly by a salinity decrease, but salinity increase was observed as well. Indeed, Argo float observations from the tropical and subtropical Atlantic (Fig. 8) revealed a largescale salinity increase between $10^{\circ} \mathrm{S}$ and $10^{\circ} \mathrm{N}$ in the depth of the deep oxycline (around density surface $26.8 \mathrm{~kg} \mathrm{~m}^{-3}$ ). In contrast, in the IW layer (here shown for density surface $27.2 \mathrm{~kg} \mathrm{~m}^{-3}$ ) the salinity increase was weaker and less homogeneous, regionally alternating with salinity decrease as exemplarily shown for the $23^{\circ} \mathrm{W}$ section.

Argo float observations further suggest that this salinity increase in the tropical Atlantic might be due to a northward migration of positive salinity anomalies advected from the Southern Hemisphere to the Northern Hemisphere along the western boundary. This is in agreement with the generally expected shallow northward propagation of SAW due to the presence of the STC and the AMOC (Lübbecke et al., 2015; Kirchner et al., 2009; Rabe et al., 2008; Biastoch et al., 2009). However, a continuous pathway of propagating positive salinity anomalies along the western boundary into the ETNA could barely be observed. We speculate that the analyzed data set of Argo float observations was too sparse (particularly in the narrow and energetic western boundary current regime) to identify a continuous propagation of these signals.

Different mechanisms may have caused the positive salinity anomalies in the South Atlantic: (i) a change in the Agulhas leakage (Kolodziejczyk et al., 2014; Hummels et al., 2015; Biastoch et al., 2009; Lübbecke et al., 2015) or (ii) a change in the subduction rate in the subtropical South Atlantic (Liu and Huang, 2012). Both scenarios might have gone along with a change in the water mass age and thus with a change in the ventilation time of the ETNA. However, (iii) global warming could be another cause for the observed change in the salinity distribution (vertical displacement of isopycnal surfaces in the tropical Atlantic or horizontal displacement of isopycnal surfaces in the subduction regimes in the subtropics).

\subsection{Role of circulation changes}

The generally inversely related decadal changes in oxygen and salinity (Fig. 6 and Table 3 ) in the ETNA along $23^{\circ} \mathrm{W}$ suggest a change in the circulation pattern of the tropical Atlantic (200-400 m: weakened ventilation; below $400 \mathrm{~m}$ : intensified ventilation). This is in line with the shoaling of the ETNA OMZ (Fig. 9; see also Sect. 4.1), with the deepening of isopycnal surfaces in the OMZ regime between 7 and $11^{\circ} \mathrm{N}$ as well as with the shoaling of isopycnal surfaces north and south of this latitude band (Fig. 10).

Changes in circulation and ventilation in the ETNA may be driven either by local or remote processes. Remote processes were already qualitatively discussed in Sect. 4.1 along with salinity changes in the tropical and subtropical Atlantic. Exemplarily, an increasing Agulhas leakage would result in positive salinity anomalies in the subtropical South Atlantic (Biastoch et al., 2009; Kolodziejczyk et al., 2014), which is assumed to go along with negative oxygen anoma- 
lies and larger water ages of Indian Ocean CW and IW. Further, changes in the subduction rate in the subtropical South Atlantic or North Atlantic or a horizontal displacement of isopycnal surfaces in these subduction regimes would change the ventilation as well. A quantitative analysis of these remote processes with respect to ventilation changes in the ETNA is challenging and goes beyond the scope of this study. In the following, we concentrate on local processes in the tropical Atlantic, which might have particularly driven circulation changes in the ETNA.

In the deep oxycline (200-400 m), advection of SAW from the western boundary is an important factor for the ventilation of the ETNA (see Figs. 2 and 8 in this study; see also Hahn et al., 2014, Brandt et al., 2015, Pena-Izquierdo et al., 2015, Lübbecke et al., 2015). Thus, it is likely that interannual to decadal variability in the position and strength of the largely wind-driven currents in the top few hundred meters might have caused the changes in oxygen and salinity. Repeated $23^{\circ} \mathrm{W}$ sections did not show a large-scale change in the strength of the zonal velocity (Fig. 11). However, the analysis of altimetry-based surface zonal geostrophic velocity revealed a strengthening of the eastward velocity between 4 and $6^{\circ} \mathrm{N}$ (NECC) and a weakening between 6 and $10^{\circ} \mathrm{N}$ (nNECC) from 2006 to 2015 (Fig. 12d), which is associated with a southward shift of the wind-driven gyres of the tropical North Atlantic. These circulation changes result in a weakened ventilation of the ETNA from the western boundary in the latitude range of the $\mathrm{OMZ}$, which is in agreement with the observed decadal change patterns of oxygen and salinity in this depth range.

A distinct change in the current field was found directly south of the Cabo Verde islands (Fig. 11). The band of eastward velocity shifted toward south (from $14^{\circ} \mathrm{N}$ to $12-$ $13^{\circ} \mathrm{N}$ ) and a band of weak westward velocity was observed instead around $13-14^{\circ} \mathrm{N}$ during the more recent period. This can be associated with a southward shift of the Cape Verde Current (CVC; Pena-Izquierdo et al., 2015), which is thought to predominantly advect NAW. However, it remains uncertain whether a southward shift of the CVC has contributed to a change in the ratio of NAW and SAW, and to a (de)oxygenation in the upper $400 \mathrm{~m}$ of the water column. Note that, in contrast to shipboard observations, the southward shift of the CVC was not similarly found in the dominant EOF pattern of altimetry-based surface zonal geostrophic velocity (Fig. 12). We suspect several reasons for this difference. First, the zonal (and also meridional) extent as well as the amplitude of the coherent variability pattern of the surface zonal geostrophic velocity are larger between 4 and $10^{\circ} \mathrm{N}$ than between 10 and $14^{\circ} \mathrm{N}$. Second, the CVC has its core below the surface, as shown in the mean velocity section along $23^{\circ} \mathrm{W}$ (Fig. 2c; see also Pena-Izquierdo et al., 2015). The maximum variability of this current is likely at the subsurface as well. Third, shipboard observations represent only snapshots of the strongly variable current field, possibly resulting in an aliasing of short-term variability.
In addition to the decadal change, moored observations have also revealed pronounced oxygen and salinity variability on interannual timescales. Associated interannual to decadal variability of the wind-driven circulation in the tropical Atlantic is predominantly driven by ocean-atmosphere interactions related to Atlantic climate modes, namely the Atlantic Zonal Mode (AZM) and Atlantic Meridional Mode (AMM) (Chang et al., 2006; Joyce et al., 2004; Marshall et al., 2001; Zhu et al., 2012). Servain (1991) introduced the AZM as the equatorial sea surface temperature (SST) anomaly and defined the AMM as the anomalous interhemispheric SST gradient with negative AMM corresponding to a negative/positive SST anomaly in the Northern Hemisphere/Southern Hemisphere. A negative AZM or a positive AMM was found to be associated with a northward shift and a strengthening of the NECC (Hormann et al., 2012). Although both climate modes are not correlated with each other, the authors report one of the strongest negative/positive AZMs/AMMs in the year 2005 and a phase of intense positive/negative AZMs/AMMs in the years 2008-2010 (particularly, see Foltz et al., 2012 for the strong negative AMM in 2009). These phases are related to an anomalous strengthening as well as northward shift (in the earlier period) and a weakening as well as southward shift (in the latter period) of the NECC, respectively. Similar analyses in our study showed a still-persistent anomalous southern position of the NECC in recent years (Fig. 12) - superimposed by interannual variability in NECC strength and position - resulting in almost a full decade of weakened ventilation of the upper $300 \mathrm{~m}$ in the ETNA.

The AMM has recently been shown to be interrelated to the Guinea Dome variability (Doi et al., 2010), where a negative AMM in boreal spring is connected to a southward shift of the ITCZ as well as a weaker Guinea Dome. The aforementioned multi-annual negative AMM phase might be associated with a comprehensive weakening of the near-surface circulation on interannual to decadal timescales, which contributed to a weakened ventilation and subsequently to the average negative oxygen trend in the deep oxycline in the recent decade.

Below $400 \mathrm{~m}$, the large-scale oxygen increase along $23^{\circ} \mathrm{W}$ pointed to an intensification of the ventilation of the ETNA throughout the past decade. A likely reason is a strengthening of the LAZJs during the past decade compared to the decade before, subsequently causing the oxygen increase. Time coverage of velocity data was generally too sparse and too short to conduct a profound analysis of the interannual to decadal velocity variability (neither for Argo, Rosell-Fieschi et al., 2015 , nor ship section data in this study). However, we found a slight broadening and intensification of the eastward jet at about $9^{\circ} \mathrm{N}$ and a southward shift of the CVC from 13.5 to $12.5^{\circ} \mathrm{N}$ (Fig. 11) for the recent 1.5 decades. This change in the velocity field is reasonably reflected in the decadal change pattern of oxygen and salinity. The eastward jet at $9^{\circ} \mathrm{N}$ advected more SAW (fresh, oxygenated) from the west- 


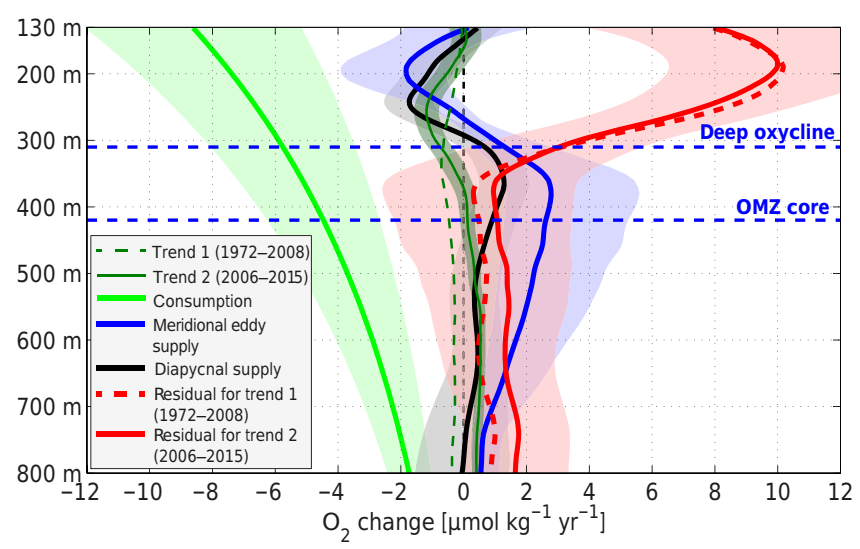

Figure 13. Oxygen budget for the ETNA as an average between 6 and $14^{\circ} \mathrm{N}$ (see Eq. (1) and corresponding text in Sects. 2.5, 3.4 and 4.3 for details). The terms consumption, meridional eddy supply and diapycnal supply were kept constant in time, whereas two different oxygen trends for the periods 1972-2008 (multi-decadal trend: dashed green line) and 2006-2015 (decadal trend: solid green line) were implemented in the budget. The corresponding residual supply for both periods (multi-decadal: dashed red line - decadal: solid red line) was calculated by assuming a balance between all respective terms.

ern boundary. In addition, the southward shifted CVC may have led to an advection of more oxygenated water at $13^{\circ} \mathrm{N}$. If we assume a time-invariant oxygen consumption, higher oxygenated water supplied by eastward jets agrees well with the only little oxygen gain found in the recirculated water of adjacent westward current bands at 7 and $11^{\circ} \mathrm{N}$. This result is not contradictory to the deoxygenation at 200 to $400 \mathrm{~m}$ depth: LAZJs are low baroclinic mode currents (e.g., Qiu et al., 2013) which are superimposed on the strong wind-driven current field of the upper $350 \mathrm{~m}$ (Rosell-Fieschi et al., 2015). The comparatively small temporal variability of the LAZJs is assumed to have only weak impact on the oxygen and water mass variability in the upper ocean.

Hahn et al. (2014) showed that lateral mixing is a dominant driver in supplying the OMZ below $400 \mathrm{~m}$ through its meridional boundaries. Tropical instability waves, acting at the southern boundary at about $5^{\circ} \mathrm{N}$, have varied in strength throughout the past decade, potentially leading to a temporal change in the ventilation. They were anomalously weak in the years 2006-2008 and strengthened afterward in the years 2009-2010 (Perez et al., 2012). This may explain the pronounced interannual variability at $5^{\circ} \mathrm{N}$ in comparison to 8 and $11^{\circ} \mathrm{N}$ (Figs. 3-5); a possible effect of decadal changes in the strength of the lateral mixing on the oxygen variability cannot be addressed with the available data. However, an increase of the meridional eddy diffusivity would have also affected the upper $400 \mathrm{~m}$. We suspect that an increasing meridional eddy diffusion on interannual to decadal timescales would have projected the band structure of the eddy-driven meridional oxygen supply (latitudinally alternating loss and

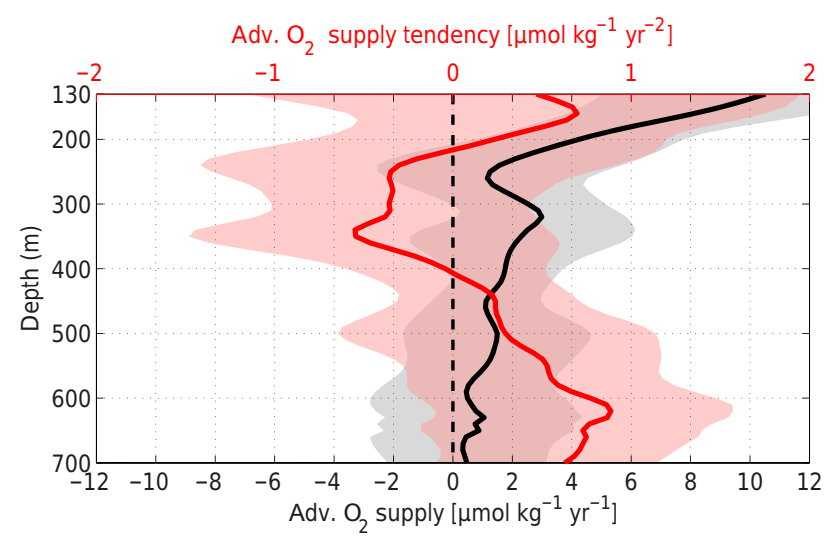

Figure 14. Vertical profiles of the mean zonal advective oxygen supply across $23^{\circ} \mathrm{W}$ (black) and the respective zonal advective oxygen supply tendency (red) calculated from shipboard observations along $23^{\circ} \mathrm{W}$ and referred to the $23-15^{\circ} \mathrm{W}$ and $6-14^{\circ} \mathrm{N}$ box. Gray and red shadings define the $95 \%$ confidence band of the mean zonal advective oxygen supply and the zonal advective oxygen supply tendency, respectively.

gain of oxygen; cf. Fig. 11 in Hahn et al., 2014) into the decadal change pattern of oxygen. Thus, an exclusive intensification of the lateral eddy diffusion does not reasonably fit with the observed variability patterns.

\subsection{Oxygen budget for decadal and multi-decadal oxygen changes}

A time-varying oxygen budget of the ETNA $\left(6-14^{\circ} \mathrm{N}\right)$ was evaluated by including both the decadal and multi-decadal oxygen trend (Fig. 13) in order to discuss potential changes in the ventilation terms (lateral mixing, diapycnal mixing, advection). The following discussion shall strengthen the argumentation on decadal changes in the ventilation given in the last section. This includes a quantitative estimate of decadal changes in the ventilation terms with respect to their potential in having caused the decadal oxygen change.

Brandt et al. (2010) argued that a weakening of the zonal jets over the past decades might have contributed to the average multi-decadal deoxygenation in the ETNA OMZ. In fact, the authors found a multi-decadal oxygen decrease over the whole depth range between 100 and $1000 \mathrm{~m}$, which is likely the result of a weakening of the wind-driven, surfaceintensified zonal currents (NECC, nNECC) as well as the low baroclinic mode LAZJs. Multi-decadal changes in the STC or the MOC might have led to long-term changes in the oceanic oxygen concentration as well (Duteil et al., 2014a), but no relation to oxygen was shown so far for the ETNA.

In the recent decade, oxygen decreased above the OMZ core (shallower than $400 \mathrm{~m}$ ) and increased below. Diapycnal supply and meridional eddy supply were assumed to be time invariant in the oxygen budget, and time dependence was included in the residual oxygen supply (cf. Eq. 1) mainly as- 
sociated with zonal advection. First, the slight shoaling of the residual supply in the upper $350 \mathrm{~m}$ indicated a weakening and shoaling of the near-surface circulation resulting in a weakened ventilation of the ETNA. Second, the vertically homogeneous increase of the residual supply below $400 \mathrm{~m}$ suggested a homogeneous strengthening of the circulation over depth. Obviously, this homogeneous change in the residual supply fits best with the structure of the residual supply profile itself, whereas temporal variability in the diapycnal or meridional eddy supply would likely have led to a non-homogeneous change over depth in the oxygen supply. We shall additionally note that almost at the depth of strongest negative multi-decadal oxygen trend, the decadal oxygen trend is zero, switching from negative (above) to positive (below). This depth also coincides with the minimum of the residual oxygen supply, separating a region with a strong near-surface supply from the region with weaker, depth-independent supply below. The different vertical structures of the decadal and multi-decadal trends, together with the residual supply profile, further suggest different ventilation mechanisms at work on different timescales.

It might be argued that a depth-independent oxygen trend below $400 \mathrm{~m}$ could have been induced by a temporal change of several processes superimposing each other in the oxygen budget. Lateral eddy diffusion has already been ruled out as the main driver for this decadal trend (Sect. 4.2). Decadal variability in the diapycnal supply, which is parameterized as a diffusive process given as $-\frac{\partial}{\partial z} \Phi=\frac{\partial}{\partial z}\left(\rho K_{\rho} \frac{\partial}{\partial z} \mathrm{O}_{2}\right.$ ) (with diapycnal oxygen flux $\Phi$, density $\rho$, diapycnal diffusivity $K_{\rho}$ and vertical oxygen gradient $\frac{\partial}{\partial z} \mathrm{O}_{2}$; Fischer et al., 2013), has not explicitly been investigated so far. The question is how much of a change in $K_{\rho}$ is required to explain the observed trend. The trend was typically found in the range $\pm 1 \mu \mathrm{mol} \mathrm{kg}{ }^{-1} \mathrm{yr}^{-1}$, which is the same order of magnitude as the diapycnal oxygen supply itself. Hence, $K_{\rho}$ needed to have varied by a factor of 2 to explain this trend. Recent observational (2008-2015) studies quantified $K_{\rho}$ for the ETNA and found only slight differences between $1.0 \times 10^{-5}$ and $1.19 \times 10^{-5} \mathrm{~m}^{2} \mathrm{~s}^{-1}$ (with $95 \%$ confidence limits $0.8 \times 10^{-5}$ and $\left.1.4 \times 10^{-5} \mathrm{~m}^{2} \mathrm{~s}^{-1}\right)$ in the depth range of 150 to $600 \mathrm{~m}$ (Banyte et al., 2012; Fischer et al., 2013; Köllner et al., 2016). Such a marginal variability in the strength of the diapycnal mixing cannot solely account for the observed oxygen trend - neither for the deoxygenation in the deep oxycline nor for the oxygenation in the OMZ core. Note also that constant diffusivities would always act to damp a weakening or strengthening of an oxygen minimum.

Strictly, a straightforward estimate of the advective oxygen supply can be derived only by accounting all advective fluxes across the boundary of a closed volume. This cannot be achieved for the ETNA OMZ with the data set given at hand. Nevertheless, in order to strengthen our discussion about the physical drivers of the observed decadal oxygen tendency, we provide an estimate of the zonal advective oxygen supply to the ETNA OMZ by evaluating only data taken along the $23^{\circ} \mathrm{W}$ section as presented in the following. First, we define a box $\left(23-15^{\circ} \mathrm{W}\right.$ and $\left.6-14^{\circ} \mathrm{N}\right)$ and assume that the dominant advective ventilation of this box is zonally across the $23^{\circ} \mathrm{W}$ section. Fluxes across the northern, southern and eastern boundaries of the box are neglected. Note that the eastern boundary of this box is roughly given by the western margin of the African continent. Further, we weight the eastward and westward advective oxygen flux to account for a possible mass imbalance across $23^{\circ} \mathrm{W}$. The oxygen flux across $23^{\circ} \mathrm{W}$ associated with zonal advection can then be written as follows:

$F(z)=2\left(T_{2} F_{1}-T_{1} F_{2}\right) /\left(T_{2}-T_{1}\right)$,

with

$T_{n}=\int_{z-\Delta z / 2}^{z+\Delta z / 2} \int_{y 1}^{y 2} H\left((-1)^{n} u\right) u \mathrm{~d} y \mathrm{~d} z^{\prime}$,
$F_{n}=\int_{z-\Delta z / 2}^{z+\Delta z / 2} \int_{y 1}^{y 2} H\left((-1)^{n} u\right) \mathrm{O}_{2} u \mathrm{~d} y \mathrm{~d} z^{\prime}$

$T_{n}$ and $F_{n}$ are the mass transport and oxygen flux across $23^{\circ} \mathrm{W}$, where $n=1$ represents westward (negative) and $n=$ 2 eastward (positive) transport and fluxes, respectively. $y$ is latitude, $z$ is depth, $u$ is zonal velocity and $\mathrm{O}_{2}$ is oxygen. $H\left((-1)^{n} u\right)$ is the Heaviside function, which is 1 for $(-1)^{n} u \geq 0$ and 0 for $(-1)^{n} u<0$. The vertical resolution, $\Delta z$, was chosen to be $10 \mathrm{~m}$, and $y 1$ and $y 2$ are the southern and northern boundaries located at 6 and $14^{\circ} \mathrm{N}$, respectively. If the mass flux across this section is balanced at a given depth range, $z \pm \Delta z / 2$, i.e., $T_{2}=-T_{1}$, Eq. (2) reduces to $F(z)=F_{1}+F_{2}$. The relative mass imbalance can be defined as $\left(T_{2}+T_{1}\right) /\left(T_{2}-T_{1}\right)$. The depth-averaged value of this imbalance with $95 \%$ confidence (double standard error) for the depth range 200 to $700 \mathrm{~m}$ was $0.06 \pm 0.18$ (average over all ship sections) corresponding to a weak eastward mean flow with the imbalance generally smaller than $10 \%$. Close to the surface (above $200 \mathrm{~m}$ ), the mass imbalance was larger (10-40\%) with westward flow dominating. This flow must be balanced by the flow through the other box boundaries making the estimate of zonal advective oxygen supply across $23^{\circ} \mathrm{W}$ above $200 \mathrm{~m}$ less relevant.

Eventually, a vertical profile of the zonal advective oxygen supply was calculated for every ship section from the zonal oxygen flux given in Eq. (2) divided by the volume of the predefined box. Further, a vertical profile of the mean zonal advective oxygen supply as well as of its decadal change was calculated based on the 13 available ship sections along $23^{\circ} \mathrm{W}$ (Fig. 14). The vertical structure of both estimates is qualitatively in agreement with the residual supply and the decadal oxygen tendency, respectively, in the oxygen budget (Fig. 13), i.e., (i) strong supply above $300 \mathrm{~m}$ and reduced supply below and (ii) oxygen loss between 200 and $400 \mathrm{~m}$ and oxygen gain below. Particularly, the qualitatively reasonable vertical structure of the zonal advective oxygen sup- 
ply tendency emphasizes that changes in the zonal advection may have substantially contributed to the decadal oxygen tendency in the ETNA.

So far, the impact of vertical advection on the oxygen concentration in the ETNA was not discussed at all, as observationally based estimates of vertical velocity are rare. Even though a robust analysis is impossible, we roughly estimated the advective vertical oxygen supply by referring to a model study of Pena-Izquierdo et al. (2015), who came up with a vertical structure of the mean vertical velocity in the ETNA. From the obtained vertical velocity that is in general agreement with an observationally based estimate from Banyte et al. (2012), we constructed a vertical velocity profile with upward velocities in the UCW layer $\left(-3 \times 10^{-7} \mathrm{~m} \mathrm{~s}^{-1}\right.$ at $100 \mathrm{~m}$ or $26.3 \mathrm{~kg} \mathrm{~m}^{-3}$ ) and downward velocities in the LCW $\left(1.5 \times 10^{-7} \mathrm{~m} \mathrm{~s}^{-1}\right.$ at $535 \mathrm{~m}$ or $\left.27.15 \mathrm{~kg} \mathrm{~m}^{-3}\right)$, and a zero crossing at the interface of both layers (at $270 \mathrm{~m}$ or $26.8 \mathrm{~kg} \mathrm{~m}^{-3}$ ). We then estimated the advective vertical oxygen supply by taking the divergence of the advective vertical oxygen flux $\left(-w \partial \mathrm{O}_{2} / \partial z\right)$ and found alternating depth ranges of oxygen gain (roughly $100-180$ and $270-430 \mathrm{~m}$ ) and oxygen loss (roughly $180-270 \mathrm{~m}$ and below $430 \mathrm{~m}$ ) with magnitudes of up to $0.3 \mu \mathrm{mol} \mathrm{kg}{ }^{-1} \mathrm{yr}^{-1}$ (not shown). Even though this term seems to be up to 5 to 10 times smaller than other oxygen supply terms, its vertical structure in the depth of the OMZ is qualitatively similar to the vertical structure of the observed decadal oxygen change (Figs. 6a and 13). This indicates that a decadal change of the advective vertical oxygen supply could have additionally contributed to the decadal oxygen change.

\section{Summary and conclusion}

Based on moored, repeat shipboard, Argo float and altimetry observations carried out mainly in the region of the ETNA OMZ, this study quantified decadal changes of hydrography and oxygen during the past decade (2006-2015) and aimed to relate these changes to changes in circulation and ventilation. A time-dependent oxygen budget of the ETNA was evaluated and decadal to long-term changes of oxygen supply pathways were discussed. The major results are the following.

i. In the past decade, the ETNA was subject to an accelerated oxygen decrease around the deep oxycline (200-400 m) and a large-scale depth-independent oxygen increase below $400 \mathrm{~m}$ (Fig. 6a), which is associated with weakened and strengthened ventilation, respectively (Fig. 15). This decadal oxygen change pattern is superimposed on the multi-decadal deoxygenation pattern observed in recent studies for the ETNA (Stramma et al., 2008; Brandt et al., 2015). While the decadal change in the oxygen distribution was shown to be mainly associated with an upward migration of the OMZ core in density and depth space, the multidecadal oxygen decrease, that is found above and below

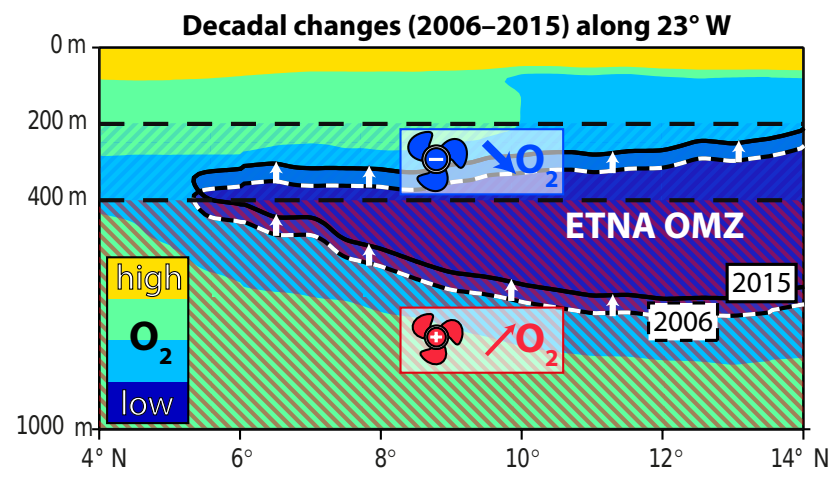

Figure 15. Schematic description of oxygen change associated with ventilation change in the ETNA along $23^{\circ} \mathrm{W}$ in the period 20062015. The $x$ axis indicates latitude; $y$ axis indicates depth; color shading denotes the oxygen distribution (yellow: high oxygen; dark blue: low oxygen). In the depth layer $200-400 \mathrm{~m}$, ventilation has weakened, resulting in a strong oxygen decrease (indicated by the blue fan and the blue downward arrow with symbol $\mathrm{O}_{2}$ ). In the depth layer 400-1000 m, moderate oxygen increase was found associated with a preceding strengthening of the ventilation (red fan and red upward arrow with symbol $\mathrm{O}_{2}$ ). As a result of the ventilation and oxygen changes, the ETNA OMZ has migrated upward (white arrows); the black-white dashed and black contour lines indicate the extent of the OMZ for the years 2006 and 2015, respectively.

the deep oxycline, is associated with a northward shift of the OMZ.

ii. The decadal oxygen change was predominantly inversely related to the decadal salinity change in the $\mathrm{CW}$ and IW layers $(>200 \mathrm{~m}$ ) south of the OMZ core (cf. Figs. 6a, c and 7d). In particular, a large-scale salinity increase was observed for the tropical Atlantic $\left(10^{\circ} \mathrm{S}-\right.$ $10^{\circ} \mathrm{N}$ ) at the depth of the deep oxycline, potentially going along with a propagation of a positive salinity anomaly from the Southern Hemisphere across the Equator toward the ETNA (Fig. 8).

iii. The decadal oxygen decrease and salinity increase around the deep oxycline $(200-400 \mathrm{~m})$ of the ETNA were associated with local and remote circulation changes. A weakening and southward shift of the winddriven current field between 5 and $10^{\circ} \mathrm{N}$ (NECC, nNECC) - which are likely related to changes in the large-scale wind-stress curl - or a southward shift of the CVC between 12 and $14^{\circ} \mathrm{N}$ might have directly led to a weakened ventilation of the ETNA (Figs. 11 and 12). Changes in the Agulhas leakage (Kolodziejczyk et al., 2014; Hummels et al., 2015; Biastoch et al., 2009; Lübbecke et al., 2015) or the subduction rate in the subtropical South Atlantic (Liu and Huang, 2012) might have changed the characteristics of SAW reaching the ETNA OMZ. 
iv. Below the deep oxycline $(>400 \mathrm{~m})$, a likely reason for the intensified ventilation is a strengthening of the LAZJs during the last decade (Fig. 11) that followed a period of weakened LAZJs during the decades before (Brandt et al., 2010). LAZJs are considered to be a major branch of the subsurface circulation in the ETNA.

v. The observed decadal oxygen change likely cannot be explained by changes in consumption, lateral and diapycnal diffusion, as they are not able to provide the required amplitude and/or vertical structure. Although associated with large uncertainties, changes in the oxygen supply by zonal advection across the $23^{\circ} \mathrm{W}$ section have the highest potential to explain the observed decadal oxygen changes in the ETNA OMZ (Figs. 13 and 14).

This study addressed the hydrographic and oxygen variability on intraseasonal to multi-decadal timescales in the ETNA with a focus on decadal changes. Nevertheless, a comprehensive quantitative analysis of the different physical drivers causing the superimposed variability patterns in oxygen or hydrography, as well as the variability in the oxygen supply pathways, is still lacking. Changes in oxygen and hydrography might be phase lagged to changes in the circulation and longer periods of observational data are necessary in order to capture such relations.
Coupled climate-biogeochemistry models can reproduce the observed long-term mean global deoxygenation, but they are generally not yet capable of properly simulating regionalscale changes in oxygen, oxygen supply processes or consumption (Cabre et al., 2015; Stramma et al., 2012; Duteil et al., 2014b), which makes a model-supported interpretation of our observational results challenging. However, ocean circulation and reanalysis models may be used to study circulation variability, which is generally related to climate modes like the Pacific Decadal Oscillation, the North Atlantic Oscillation, the AMOC or the AZM and AMM (Doi et al., 2010; Hormann et al., 2012; Chang et al., 2006; Marshall et al., 2001; Zhu et al., 2012). Characteristic timescales of climate modes may be associated with circulation and ventilation variability, and consequently with hydrographic and oxygen variability on similar timescales (Frölicher et al., 2009; Czeschel et al., 2012; Duteil et al., 2014a). Hence, these modes might be promising proxies for the description of decadal to multi-decadal oxygen and hydrographic variability.

Data availability. MIMOC is available at http://www.pmel.noaa. gov/mimoc/. Argo float data were collected and made freely available by the international Argo project and the national programs that contribute to it (http://doi.org/doi:10.17882/42182). The Argo data used here were downloaded in March 2016. Aviso altimetry products of surface geostrophic velocity were downloaded from http://aviso.altimetry.fr/index.php?id=1271 in July 2016 (processing date: 27 November 2015). Shipboard and mooring data are accessible at https://doi.pangaea.de/doi:10.1594/PANGAEA.869568. 


\section{Appendix A}

List of abbreviations.

\begin{tabular}{ll}
\hline AAIW & Antarctic Intermediate Water \\
ADCP & Acoustic Doppler Current Profiler \\
AMM & Atlantic Meridional Mode \\
AMOC & Atlantic Meridional Overturning Circulation \\
AZM & Atlantic Zonal Mode \\
CTD & Conductivity-temperature-depth \\
CVC & Cape Verde Current \\
CW & Central water \\
EOF & Empirical orthogonal function \\
ETNA & Eastern tropical North Atlantic \\
EUC & Equatorial Undercurrent \\
ITCZ & Intertropical Convergence Zone \\
IW & Intermediate water \\
1-ADCP & Lowered Acoustic Doppler Current Profiler \\
LAZJs & Latitudinally alternating zonal jets \\
LCW & Lower central water \\
MIMOC & Monthly, isopycnal and mixed-layer ocean climatology \\
MOC & Meridional overturning circulation \\
NACW & North Atlantic Central Water \\
NAW & North Atlantic Water \\
NBC & North Brazil Current \\
NBUC & North Brazil Undercurrent \\
NEC & North Equatorial Current \\
NECC & North Equatorial Countercurrent \\
NEUC & North Equatorial Undercurrent \\
nNECC & Northern branch of the North Equatorial Countercurrent \\
OMZ & Oxygen minimum zone \\
PC & Principle component corresponding to an empirical orthogonal function \\
SACW & South Atlantic Central Water \\
SAW & South Atlantic Water \\
STC & Subtropical cell \\
UCW & Upper central water \\
vm-ADCP & Vessel-mounted Acoustic Doppler Current Profiler \\
&
\end{tabular}


Competing interests. The authors declare that they have no conflict of interest.

Acknowledgements. This study was funded by the Deutsche Forschungsgemeinschaft as part of the Sonderforschungsbereich 754 "Climate-Biogeochemistry Interactions in the Tropical Ocean" through several research cruises with RV L'Atalante, RV Maria S. Merian, RV Meteor and RV Polarstern, by the project FOR1740 and by the Deutsche Bundesministerium für Bildung und Forschung (BMBF) as part of projects NORDATLANTIK (03F0605B, 03F0443B) and RACE (03F0651B). We thank the captains, crews, scientists and technical groups involved in the different national and international research cruises to the eastern tropical North Atlantic that contributed to collecting CTD, velocity and mooring data and making them freely available. We thank Joke Lübbecke, Marcus Dengler and Tim Fischer for helpful discussions and Robert Kopte for post-processing of the recent ship section data. Further, we thank the international Argo program and the national programs that contribute to it, which collected the data and made them freely available. The altimeter products were produced by Ssalto/Duacs and distributed by Aviso, with support from Cnes (http://www.aviso.altimetry.fr/duacs/). We thank two anonymous reviewers for fruitful comments that improved the manuscript.

The article processing charges for this open-access publication were covered by a Research

Centre of the Helmholtz Association.

Edited by: Mario Hoppema

Reviewed by: two anonymous referees

\section{References}

Argo: Argo float data and metadata from Global Data Assembly Centre (Argo GDAC), SEANOE, 2000, available at: http://doi. org/10.17882/42182, last access: March 2016.

Ascani, F., Firing, E., Dutrieux, P., McCreary, J. P., and Ishida, A.: Deep Equatorial Ocean Circulation Induced by a ForcedDissipated Yanai Beam, J. Phys. Oceanogr., 40, 1118-1142, https://doi.org/10.1175/2010jpo4356.1, 2010.

Ascani, F., Firing, E., McCreary, J. P., Brandt, P., and Greatbatch, R. J.: The Deep Equatorial Ocean Circulation in WindForced Numerical Solutions, J. Phys. Oceanogr., 45, 1709-1734, https://doi.org/10.1175/jpo-d-14-0171.1, 2015.

Aviso, MADT-H-UV: Maps of Absolute Dynamic Topography \& absolute geostrophic velocities, available at: https://www.aviso. altimetry.fr/index.php?id=1271, last access: July 2016.

Banyte, D., Tanhua, T., Visbeck, M., Wallace, D. W. R., Karstensen, J., Krahmann, G., Schneider, A., Stramma, L., and Dengler, M.: Diapycnal diffusivity at the upper boundary of the tropical North Atlantic oxygen minimum zone, J. Geophys. Res.-Ocean., 117, C09016, https://doi.org/10.1029/2011jc007762, 2012.

Biastoch, A., Böning, C. W., Schwarzkopf, F. U., and Lutjeharms, J. R. E.: Increase in Agulhas leakage due to poleward shift of Southern Hemisphere westerlies, Nature, 462, 495-498, https://doi.org/10.1038/nature08519, 2009.
Bopp, L., Le Quéré, C., Heimann, M., Manning, A. C., and Monfray, P.: Climate-induced oceanic oxygen fluxes: Implications for the contemporary carbon budget, Global Biogeochem. Cy., 16, 6-1-6-13, https://doi.org/10.1029/2001gb001445, 2002.

Brandt, P., Hormann, V., Bourlès, B., Fischer, J., Schott, F. A., Stramma, L., and Dengler, M.: Oxygen tongues and zonal currents in the equatorial Atlantic, J. Geophys. Res.-Ocean., 113, C04012, https://doi.org/10.1029/2007jc004435, 2008.

Brandt, P., Hormann, V., Körtzinger, A., Visbeck, M., Krahmann, G., Stramma, L., Lumpkin, R., and Schmid, C.: Changes in the Ventilation of the Oxygen Minimum Zone of the Tropical North Atlantic, J. Phys. Oceanogr., 40, 1784-1801, https://doi.org/10.1175/2010jpo4301.1, 2010.

Brandt, P., Greatbatch, R. J., Claus, M., Didwischus, S. H., Hormann, V., Funk, A., Hahn, J., Krahmann, G., Fischer, J., and Körtzinger, A.: Ventilation of the equatorial Atlantic by the equatorial deep jets, J. Geophys. Res.-Ocean., 117, C12015, https://doi.org/10.1029/2012jc008118, 2012.

Brandt, P., Bange, H. W., Banyte, D., Dengler, M., Didwischus, S. H., Fischer, T., Greatbatch, R. J., Hahn, J., Kanzow, T., Karstensen, J., Körtzinger, A., Krahmann, G., Schmidtko, S., Stramma, L., Tanhua, T., and Visbeck, M.: On the role of circulation and mixing in the ventilation of oxygen minimum zones with a focus on the eastern tropical North Atlantic, Biogeosciences, 12, 489-512, https://doi.org/10.5194/bg-12-489-2015, 2015.

Bunge, L., Provost, C., Hua, B. L., and Kartavtseff, A.: Variability at intermediate depths at the equator in the Atlantic ocean in 2000-06: Annual cycle, equatorial deep jets, and intraseasonal meridional velocity fluctuations, J. Phys. Oceanogr., 38, 17941806, https://doi.org/10.1175/2008jpo3781.1, 2008.

Cabre, A., Marinov, I., Bernardello, R., and Bianchi, D.: Oxygen minimum zones in the tropical Pacific across CMIP5 models: mean state differences and climate change trends, Biogeosciences, 12, 5429-5454, https://doi.org/10.5194/bg-12-54292015, 2015.

Chang, P., Yamagata, T., Schopf, P., Behera, S. K., Carton, J., Kessler, W. S., Meyers, G., Qu, T., Schott, F., Shetye, S., and Xie, S. P.: Climate fluctuations of tropical coupled systems - The role of ocean dynamics, J. Clim., 19, 5122-5174, https://doi.org/10.1175/jcli3903.1, 2006.

Chang, P., Zhang, R., Hazeleger, W., Wen, C., Wan, X. Q., Ji, L., Haarsma, R. J., Breugem, W. P., and Seidel, H.: Oceanic link between abrupt changes in the North Atlantic Ocean and the African monsoon, Nat. Geosci., 1, 444-448, https://doi.org/10.1038/ngeo218, 2008.

Czeschel, R., Stramma, L., and Johnson, G. C.: Oxygen decreases and variability in the eastern equatorial Pacific, J. Geophys. Res.Ocean., 117, C11019, https://doi.org/10.1029/2012jc008043, 2012.

Doi, T., Tozuka, T., and Yamagata, T.: The Atlantic Meridional Mode and Its Coupled Variability with the Guinea Dome, J. Clim., 23, 455-475, https://doi.org/10.1175/2009jcli3198.1, 2010.

Duteil, O., Böning, C. W., and Oschlies, A.: Variability in subtropical-tropical cells drives oxygen levels in the tropical Pacific Ocean, Geophys. Res. Lett., 41, 8926-8934, https://doi.org/10.1002/2014g1061774, 2014a.

Duteil, O., Schwarzkopf, F. U., Böning, C. W., and Oschlies, A.: Major role of the equatorial current system in setting oxy- 
gen levels in the eastern tropical Atlantic Ocean: A highresolution model study, Geophys. Res. Lett., 41, 2033-2040, https://doi.org/10.1002/2013g1058888, 2014b.

Eden, C. and Dengler, M.: Stacked jets in the deep equatorial Atlantic Ocean, J. Geophys. Res.-Ocean., 113, C04003, https://doi.org/10.1029/2007jc004298, 2008.

Fischer, T., Banyte, D., Brandt, P., Dengler, M., Krahmann, G., Tanhua, T., and Visbeck, M.: Diapycnal oxygen supply to the tropical North Atlantic oxygen minimum zone, Biogeosciences, 10, 5079-5093, https://doi.org/10.5194/bg-10-5079-2013, 2013.

Foltz, G. R., McPhaden, M. J., and Lumpkin, R.: A Strong Atlantic Meridional Mode Event in 2009: The Role of Mixed Layer Dynamics, J. Clim., 25, 363-380, https://doi.org/10.1175/jcli-d-11$00150.1,2012$.

Frölicher, T. L., Joos, F., Plattner, G. K., Steinacher, M., and Doney, S. C.: Natural variability and anthropogenic trends in oceanic oxygen in a coupled carbon cycle-climate model ensemble, Global Biogeochem. Cy., 23, 15, GB1003, https://doi.org/10.1029/2008gb003316, 2009.

Garzoli, S. L. and Katz, E. J.: The Forced Annual Reversal of the Atlantic North Equatorial Countercurrent, J. Phys. Oceanogr., 13, 2082-2090, https://doi.org/10.1175/15200485(1983)013<2082:tfarot>2.0.co;2, 1983.

Garzoli, S. L. and Richardson, P. L.: Low-frequency meandering of the Atlantic North Equatorial Countercurrent, J. Geophys. Res.-Ocean., 94, 2079-2090, https://doi.org/10.1029/JC094iC02p02079, 1989.

Hahn, J., Brandt, P., Greatbatch, R. J., Krahmann, G., and Körtzinger, A.: Oxygen variance and meridional oxygen supply in the Tropical North East Atlantic oxygen minimum zone, Clim. Dynam., 43, 2999-3024, https://doi.org/10.1007/s00382014-2065-0, 2014.

Hahn, J., Brandt, P., Schmidtko, S., and Krahmann, G.: Oxygen, hydrography and velocity in the eastern tropical North Atlantic (1999-2015), Pangaea, https://doi.pangaea.de/10.1594/ PANGAEA.869568, 2016.

Helly, J. J. and Levin, L. A.: Global distribution of naturally occurring marine hypoxia on continental margins, Deep-Sea Res. Pt. I, 51, 1159-1168, https://doi.org/10.1016/j.dsr.2004.03.009, 2004.

Helm, K. P., Bindoff, N. L., and Church, J. A.: Observed decreases in oxygen content of the global ocean, Geophys. Res. Lett., 38, L23602, https://doi.org/10.1029/2011g1049513, 2011.

Hormann, V., Lumpkin, R., and Foltz, G. R.: Interannual North Equatorial Countercurrent variability and its relation to tropical Atlantic climate modes, J. Geophys. Res.-Ocean., 117, C04035, https://doi.org/10.1029/2011jc007697, 2012.

Hummels, R., Brandt, P., Dengler, M., Fischer, J., Araujo, M., Veleda, D., and Durgadoo, J. V.: Interannual to decadal changes in the western boundary circulation in the Atlantic at $11^{\circ} \mathrm{S}$, Geophys. Res. Lett., 42, 7615-7622, https://doi.org/10.1002/2015g1065254, 2015.

Johns, W. E., Brandt, P., Bourlès, B., Tantet, A., Papapostolou, A., and Houk, A.: Zonal structure and seasonal variability of the Atlantic Equatorial Undercurrent, Clim. Dynam., 43, 3047-3069, https://doi.org/10.1007/s00382-014-2136-2, 2014.

Joyce, T. M., Frankignoul, C., Yang, J. Y., and Phillips, H. E.: Ocean response and feedback to the SST dipole in the tropical Atlantic, J. Phys. Oceanogr., 34, 2525-2540, https://doi.org/10.1175/jpo2640.1, 2004.
Kamenkovich, I., Berloff, P., and Pedlosky, J.: Anisotropic Material Transport by Eddies and Eddy-Driven Currents in a Model of the North Atlantic, J. Phys. Oceanogr., 39, 3162-3175, https://doi.org/10.1175/2009jpo4239.1, 2009.

Karstensen, J., Stramma, L., and Visbeck, M.: Oxygen minimum zones in the eastern tropical Atlantic and Pacific oceans, Prog. Oceanogr., 77, 331-350, https://doi.org/10.1016/j.pocean.2007.05.009, 2008.

Karstensen, J., Fiedler, B., Schütte, F., Brandt, P., Körtzinger, A., Fischer, G., Zantopp, R., Hahn, J., Visbeck, M., and Wallace, D.: Open ocean dead zones in the tropical North Atlantic Ocean, Biogeosciences, 12, 2597-2605, https://doi.org/10.5194/bg-122597-2015, 2015.

Keeling, R. F. and Garcia, H. E.: The change in oceanic $\mathrm{O}_{2}$ inventory associated with recent global warming, P. Natl. Acad. Sci. USA, 99, 7848-7853, https://doi.org/10.1073/pnas.122154899, 2002.

Kirchner, K., Rhein, M., Hüttl-Kabus, S., and Böning, C. W.: On the spreading of South Atlantic Water into the Northern Hemisphere, J. Geophys. Res.-Ocean., 114, C05019, https://doi.org/10.1029/2008jc005165, 2009.

Köllner, M., Visbeck, M., Tanhua, T., and Fischer, T.: Diapycnal diffusivity in the core and oxycline of the tropical North Atlantic oxygen minimum zone, J. Mar. Syst., 160, 54-63, https://doi.org/10.1016/j.jmarsys.2016.03.012, 2016.

Kolodziejczyk, N., Reverdin, G., Gaillard, F., and Lazar, A.: Lowfrequency thermohaline variability in the Subtropical South Atlantic pycnocline during 2002-2013, Geophys. Res. Lett., 41, 6468-6475, https://doi.org/10.1002/2014gl061160, 2014.

Liu, L. L. and Huang, R. X.: The Global Subduction/Obduction Rates: Their Interannual and Decadal Variability, J. Clim., 25, 1096-1115, https://doi.org/10.1175/2011jcli4228.1, 2012.

Lübbecke, J. F., Durgadoo, J. V., and Biastoch, A.: Contribution of Increased Agulhas Leakage to Tropical Atlantic Warming, J. Clim., 28, 9697-9706, https://doi.org/10.1175/jcli-d-15-0258.1, 2015.

Luyten, J. R., Pedlosky, J., and Stommel, H.: The Ventilated Thermocline, J. Phys. Oceanogr., 13, 292-309, https://doi.org/10.1175/1520 0485(1983)013<0292:tvt>2.0.co;2, 1983.

Marshall, J., Kushner, Y., Battisti, D., Chang, P., Czaja, A., Dickson, R., Hurrell, J., McCartney, M., Saravanan, R., and Visbeck, M.: North Atlantic climate variability: Phenomena, impacts and mechanisms, Int. J. Climatol., 21, 1863-1898, https://doi.org/10.1002/joc.693, 2001.

Matear, R. J. and Hirst, A. C.: Long-term changes in dissolved oxygen concentrations in the ocean caused by protracted global warming, Global Biogeochem. Cy., 17, 1125, https://doi.org/10.1029/2002gb001997, 2003.

Maximenko, N. A., Bang, B., and Sasaki, H.: Observational evidence of alternating zonal jets in the world ocean, Geophys. Res. Lett., 32, L12607, https://doi.org/10.1029/2005gl022728, 2005.

McCreary, J. P. and Lu, P.: Interaction between the Subtropical and Equatorial Ocean Circulations: The Substropical Cell, J. Phys. Oceanogr., 24, 466-497, 1994.

Ollitrault, M. and de Verdiere, A. C.: The Ocean General Circulation near 1000-m Depth, J. Phys. Oceanogr., 44, 384-409, https://doi.org/10.1175/jpo-d-13-030.1, 2014. 
Oschlies, A., Schulz, K. G., Riebesell, U., and Schmittner, A.: Simulated 21st century's increase in oceanic suboxia by $\mathrm{CO}_{2}$ enhanced biotic carbon export, Global Biogeochem. Cy., 22, GB4008, https://doi.org/10.1029/2007gb003147, 2008.

Pena-Izquierdo, J., van Sebille, E., Pelegri, J. L., Sprintall, J., Mason, E., Llanillo, P. J., and Machin, F.: Water mass pathways to the North Atlantic oxygen minimum zone, J. Geophys. Res.Ocean., 120, 3350-3372, https://doi.org/10.1002/2014jc010557, 2015.

Perez, R. C., Lumpkin, R., Johns, W. E., Foltz, G. R., and Hormann, V.: Interannual variations of Atlantic tropical instability waves, J. Geophys. Res.-Ocean., 117, C03011, https://doi.org/10.1029/2011jc007584, 2012.

Plattner, G. K., Joos, F., and Stocker, T. F.: Revision of the global carbon budget due to changing air-sea oxygen fluxes, Global Biogeochem. Cy., 16, 12, 1096, https://doi.org/10.1029/2001gb001746, 2002.

Qiu, B., Chen, S. M., and Sasaki, H.: Generation of the North Equatorial Undercurrent Jets by Triad Baroclinic Rossby Wave Interactions, J. Phys. Oceanogr., 43, 2682-2698, https://doi.org/10.1175/jpo-d-13-099.1, 2013.

Rabe, B., Schott, F. A., and Kohl, A.: Mean circulation and variability of the tropical Atlantic during 1952-2001 in the GECCO assimilation fields, J. Phys. Oceanogr., 38, 177-192, https://doi.org/10.1175/2007jpo3541.1, 2008.

Rhein, M., Kirchner, K., Mertens, C., Steinfeldt, R., Walter, M., and Fleischmann-Wischnath, U.: Transport of South Atlantic water through the passages south of Guadeloupe and across $16^{\circ} \mathrm{N}, 2000-2004$, Deep-Sea Res. Pt. I, 52, 2234-2249, https://doi.org/10.1016/j.dsr.2005.08.003, 2005.

Richardson, P. L., Arnault, S., Garzoli, S., and Bruce, J. G.: Annual cycle of the Atlantic North Equatorial Countercurrent, DeepSea Res. Pt. A, 39, 997-1014, https://doi.org/10.1016/01980149(92)90036-s, 1992.

Roemmich, D., Johnson, G. C., Riser, S., Davis, R., Gilson, J., Owens, W. B., Garzoli, S. L., Schmid, C., and Ignaszewski, M.: The Argo Program Observing the Global Ocean with Profiling Floats, Oceanography, 22, 34-43, https://doi.org/10.5670/oceanog.2009.36, 2009.

Rosell-Fieschi, M., Pelegri, J. L., and Gourrion, J.: Zonal jets in the equatorial Atlantic Ocean, Prog. Oceanogr., 130, 1-18, https://doi.org/10.1016/j.pocean.2014.08.008, 2015.

Schmidtko, S. and Johnson, G. C.: Multidecadal Warming and Shoaling of Antarctic Intermediate Water, J. Clim., 25, 207-221, https://doi.org/10.1175/jcli-d-11-00021.1, 2012.

Schmidtko, S., Johnson, G. C., and Lyman, J. M.: Monthly Isopycnal \& Mixed-layer Ocean Climatology, available at: https://www. pmel.noaa.gov/mimoc/, 2013.

Schmidtko, S., Johnson, G. C., and Lyman, J. M.: MIMOC: A global monthly isopycnal upper-ocean climatology with mixed layers, J. Geophys. Res.-Ocean., 118, 1658-1672, https://doi.org/10.1002/jgrc.20122, 2013.

Schmidtko, S., Stramma, L., and Visbeck, M.: Decline in global oceanic oxygen content during the past five decades, Nature, 542, 335-339, https://doi.org/10.1038/nature21399, 2017.

Schmittner, A., Oschlies, A., Matthews, H. D., and Galbraith, E. D.: Future changes in climate, ocean circulation, ecosystems, and biogeochemical cycling simulated for a business-as-usual $\mathrm{CO}_{2}$ emission scenario until year $4000 \mathrm{AD}$, Global Biogeochem. Cy. 22, GB1013, https://doi.org/10.1029/2007gb002953, 2008.

Schott, F. A., Dengler, M., Brandt, P., Affler, K., Fischer, J., Bourlès, B., Gouriou, Y., Molinari, R. L., and Rhein, M.: The zonal currents and transports at $35^{\circ} \mathrm{W}$ in the tropical Atlantic, Geophys. Res. Lett., 30, 1349, https://doi.org/10.1029/2002g1016849, 2003.

Schott, F. A., McCreary, J. P., and Johnson, G. C.: Shallow Overturning Circulations of the Tropical-Subtropical Oceans, in: Earth's Climate, edited by: Wang, C., S. P., X., and J. A., Carton, American Geophysical Union, Washington, DC, 261-304, 2004.

Schott, F. A., Dengler, M., Zantopp, R., Stramma, L., Fischer, J., and Brandt, P.: The shallow and deep western boundary circulation of the South Atlantic at $5^{\circ}-11^{\circ} \mathrm{S}$, J. Phys. Oceanogr., 35, 2031-2053, https://doi.org/10.1175/jpo2813.1, 2005.

Schütte, F., Karstensen, J., Krahmann, G., Hauss, H., Fiedler, B., Brandt, P., Visbeck, M., and Körtzinger, A.: Characterization of dead-zone eddies in the eastern tropical North Atlantic, Biogeosciences, 13, 5865-5881, https://doi.org/10.5194/bg-135865-2016, 2016.

Servain, J.: Simple climatic indices for the tropical Atlantic Ocean and some applications, J. Geophys. Res.-Ocean., 96, 1513715146, https://doi.org/10.1029/91jc01046, 1991.

Stendardo, I. and Gruber, N.: Oxygen trends over five decades in the North Atlantic, J. Geophys. Res.-Ocean., 117, C11004, https://doi.org/10.1029/2012jc007909, 2012.

Stramma, L. and Schott, F.: The mean flow field of the tropical Atlantic Ocean, Deep-Sea Res. Pt. II, 46, 279-303, https://doi.org/10.1016/s0967-0645(98)00109-x, 1999.

Stramma, L., Hüttl, S., and Schafstall, J.: Water masses and currents in the upper tropical northeast Atlantic off northwest Africa, J. Geophys. Res.-Ocean., 110, C12006, https://doi.org/10.1029/2005jc002939, 2005.

Stramma, L., Johnson, G. C., Sprintall, J., and Mohrholz, V.: Expanding oxygen-minimum zones in the tropical oceans, Science, 320, 655-658, https://doi.org/10.1126/science.1153847, 2008.

Stramma, L., Visbeck, M., Brandt, P., Tanhua, T., and Wallace, D.: Deoxygenation in the oxygen minimum zone of the eastern tropical North Atlantic, Geophys. Res. Lett., 36, L20607, https://doi.org/10.1029/2009g1039593, 2009.

Stramma, L., Schmidtko, S., Levin, L. A., and Johnson, G. C.: Ocean oxygen minima expansions and their biological impacts, Deep-Sea Res. Pt. I, 57, 587-595, https://doi.org/10.1016/j.dsr.2010.01.005, 2010.

Stramma, L., Oschlies, A., and Schmidtko, S.: Mismatch between observed and modeled trends in dissolved upper-ocean oxygen over the last $50 \mathrm{yr}$, Biogeosciences, 9, 4045-4057, https://doi.org/10.5194/bg-9-4045-2012, 2012.

Thomsen, S., Kanzow, T., Colas, F., Echevin, V., Krahmann, G., and Engel, A.: Do submesoscale frontal processes ventilate the oxygen minimum zone off Peru?, Geophys. Res. Lett., 43, 81338142, https://doi.org/10.1002/2016gl070548, 2016.

Wallace, D. W. R. and Bange, H. W.: Introduction to special section: Results of the Meteor 55: Tropical SOLAS expedition, Geophys. Res. Lett., 31, L23S01, https://doi.org/10.1029/2004g1021014, 2004. 
Wyrtki, K.: The oxygen minima in relation to ocean circulation, Deep-Sea Res., 9, 11-23, https://doi.org/10.1016/00117471(62)90243-7, 1962.

Zhang, D. X., McPhaden, M. J., and Johns, W. E.: Observational evidence for flow between the subtropical and tropical Atlantic: The Atlantic subtropical cells, J. Phys. Oceanogr., 33, 17831797, https://doi.org/10.1175/2408.1, 2003.
Zhu, J. S., Huang, B. H., and Wu, Z. H.: The Role of Ocean Dynamics in the Interaction between the Atlantic Meridional and Equatorial Modes, J. Clim., 25, 3583-3598, https://doi.org/10.1175/jcli-d-11-00364.1, 2012. 